\title{
BOOSTER HEAVY ION ACCELERATION CYCLES \\ WITH CHANGE OF HARMONIC
}

BOOSTER TECHNICAL NOTE

NO. 199

D. P. DENG and J. M. BRENNAN

SEPTEMBER 12, 1991

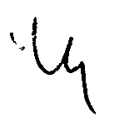

\footnotetext{
ALTERNATING GRADIENT SYNCHROTRON DEPARTMENT BROOKHAVEN NATIONAL LABORATORY UPTON, NEW YORK 11973
} 


\title{
Booster Heavy Ion Acceleration Cycles with Change of Harmonic Numbers
}

\author{
D.-P. Deng and J.M. Brennan \\ Brookhaven National Laboratory \\ Upton, Long Island, NY 11973
}

August 29, 1991

\section{Introduction}

To accelerate heavy ions in the Booster with the third harmonic system, the original Booster Design Manual calls for constructions of two Band I, one Band II and two Band III cavities. Band I, II and III cavities cover frequency ranges from $178 \mathrm{kHz}$ to $675 \mathrm{kHz}$, from $600 \mathrm{kHz}$ to $2.5 \mathrm{MHz}$ and from $2.4 \mathrm{MHz}$ to $4.2 \mathrm{MHz}$ respectively. Now it is decided to build two Band II cavities and utilize them along with two Band III cavities to accelerate heavy ions. The modified acceleration scenario goes as follows. Step 1 is to use Band II with a higher harmonic number to capture and accelerate heavy ions; step 2 is to debunch the beam when the RF frenquency reaches $2.4 \mathrm{M} \mathrm{Hz}$; the final step is to use Band II to recapture and accelerate heavy ions with harmonic number 3 , and as the $\mathrm{RF}$ frequency reaches $2.4 \mathrm{M} \mathrm{Hz}$, Band III starts to take over and accelerate heavy ions to their top energy. Note the third harmonic system spans over Band II and Band III.

This note designs acceleration cycles for silicon ions $S i^{+14}$ and gold ions $A u^{+33}$. For $A u^{+33}$, cycles with harmonic number 12 and 9 are presented. For $S i^{+14}$, a cycle with harmonic number 6 is presented.

\section{Capture and Longitudinal Emittance}

Since the heavy ion beams from the Tandem Van de Graaff have virtually zero energy spread, the initial bucket area at capture determines the initial longitudinal emittance. If adiabaticity applies, the longitudinal emittance is conserved throughout the cycle. We may take the initial bucket area at capture as the longitudinal emittance in the higher harmonic system. The total emittance, being the sum of the emittances of all bunches, is assumed to be a constant. Before and after the change of harmonic number, the total emittance is equally distributed in the bunches.

Let's take a look at the dependence of the final emittance (in unit $\mathrm{eVs}$ ) in the third harmonic system on the initial higher harmonic number. The initial longitudinal emittance is taken as the bucket area at injection, which has a dependence on the harmonic number as $h^{-\frac{3}{2}}$. Then the final emittance will be proportional to $h * h^{-\frac{3}{2}}=h^{-\frac{1}{2}}$. So provided everything else is the same, the final emittance in the third harmonic system is inversely proportional to the square root of the initial harmonic number. The higher the initial harmonic number, the smaller the final emittance.

If the capture takes place at constant magnetic field, the initial and the final emittance vary as the sqare root of the initial voltage. The smaller the voltage, the smaller the emittance. 


\section{Acceleration Cycles}

To reduce the loss of particles at capture, it is prefered to use a stationary bucket. However, for the ease of injection process, a moving bucket with small synchronous phase angle is adopted in this note.

The injection time window is assumed to be $30 \mathrm{~ms}$, injection can happen at any moment in this time interval. The time to ramp up and ramp down for the cavity voltages is assumed as 5 times of the synchrotron oscillation period, i.e. $\frac{5}{f_{\nu}}$, where $f_{\nu}$ is evaluated at the maximum of $\mathrm{RF}$ voltage; the time period to ramp up and ramp down of the rate of change of the magnetic field is taken as $10 \mathrm{~ms}$; the coasting time is $50 \mathrm{~ms}$ and is a very conservative estimate of the time needed to retune the Band II cavities. The form of ramp up (down) for the voltage and the rate of change of magnetic field is a portion of sine function from valley to peak (from peak to valley). Thus the variation of the voltage and the rate of change of the magnetic field is a continuous and smooth function.

The important parameters presented in this note are $\mathrm{RF}$ frequency $f_{r f}, \dot{\mathcal{B}}$, dipole field $\mathcal{B}$, kinetic energy $K$, bucket area $A_{b k t}$, synchronous phase angle $\phi_{s}$, voltage $V_{r f}$, synchrotron oscillation frequency $f_{\nu}$, bucket length and bunch length.

At injection, the $\dot{\mathcal{B}}$ is set at $0.05 T / \mathrm{s}$. After the injection period $(30 \mathrm{~ms}), \dot{\mathcal{B}} \operatorname{ramps}$ up to $2.5 T / \mathrm{s}$ and then stays at that value. When the RF frenquency approaches $2.4 M H z, \dot{\mathcal{B}}$ starts to ramp down and reaches zero when the RF frenquency is $2.4 \mathrm{MHz}$. The initial RF voltage is set at $1.0 \mathrm{kV}$, then it is ramped up to $15.0 \mathrm{kV}$ in roughly $2 \mathrm{~ms}$ (five times of the synchrotron oscillation period) and sustains. When $\dot{\mathcal{B}}$ is reduced to zero, the voltage is then ramped down to zero as the debunching process takes place. The RF frequency program is changed to the new harmonic number while the Gauss clock continues to track small variations in the magnetic field. The cavity is retuned to the new $\mathrm{RF}$ frequency and the voltage is ramped from zero up to $15.0 \mathrm{kV}$. When the voltage gains a value of $15.0 \mathrm{kV}, \dot{\mathcal{B}}$ starts to ramp up to $2.5 T / \mathrm{s}$.

Figures (1)--(12) depict the process for a harmonic number $h=12$. The final longitudinal emittance is $3.9 \mathrm{eVs}$ (or $0.020 \mathrm{eVs} / u$ ). Figures (13)-(24) depict the process for a harmonic number $h=9$. The final longitudinal emittance is $4.5 \mathrm{eVs}$ (or $0.023 \mathrm{eVs} / u$ ). Note during the debunching period including the end points, the bucket areas, bucket lengths and bunch lengths are all set to zero.

Figures (25)-(36) depict the process for a harmonic number $h=6$ for $S i^{+14}$, the final emittance is $1.37 \mathrm{eVs}$ (or $0.049 \mathrm{eVs} / \mathrm{u}$ ). As a side note, harmonic number 4 or $5 \mathrm{can}$ also be used in order to use a wider frequency range in Band II; though the final emittance would be a little larger.

\begin{tabular}{||c|c|c|c|c|c|c|c|c|c||}
\hline & $\beta$ & $\begin{array}{c}f_{i n j} \\
(M H z) \\
h=12\end{array}$ & $\begin{array}{c}f_{i n j} \\
(M H z) \\
h=9\end{array}$ & $\begin{array}{c}f_{i n j} \\
(M H z) \\
h=6\end{array}$ & $\begin{array}{c}E_{i n j} \\
(G e V)\end{array}$ & $\begin{array}{c}B_{i n j} \\
(T)\end{array}$ & $\begin{array}{c}f_{e j} \\
(M H z)\end{array}$ & $\begin{array}{c}E_{e j} \\
(G e V)\end{array}$ & $\begin{array}{c}B_{e j} \\
(T)\end{array}$ \\
\hline$S i^{+14}$ & 0.1194 & & & 1.0643 & 0.188 & 0.05428 & 4.0 & 32.86 & 0.9184 \\
\hline$A u^{+33}$ & 0.0478 & 0.8524 & 0.6393 & & 0.210 & 0.0645 & 3.061 & 68.95 & 1.2743 \\
\hline
\end{tabular}

Tablc 1: Some parameters at injection and ejection. 


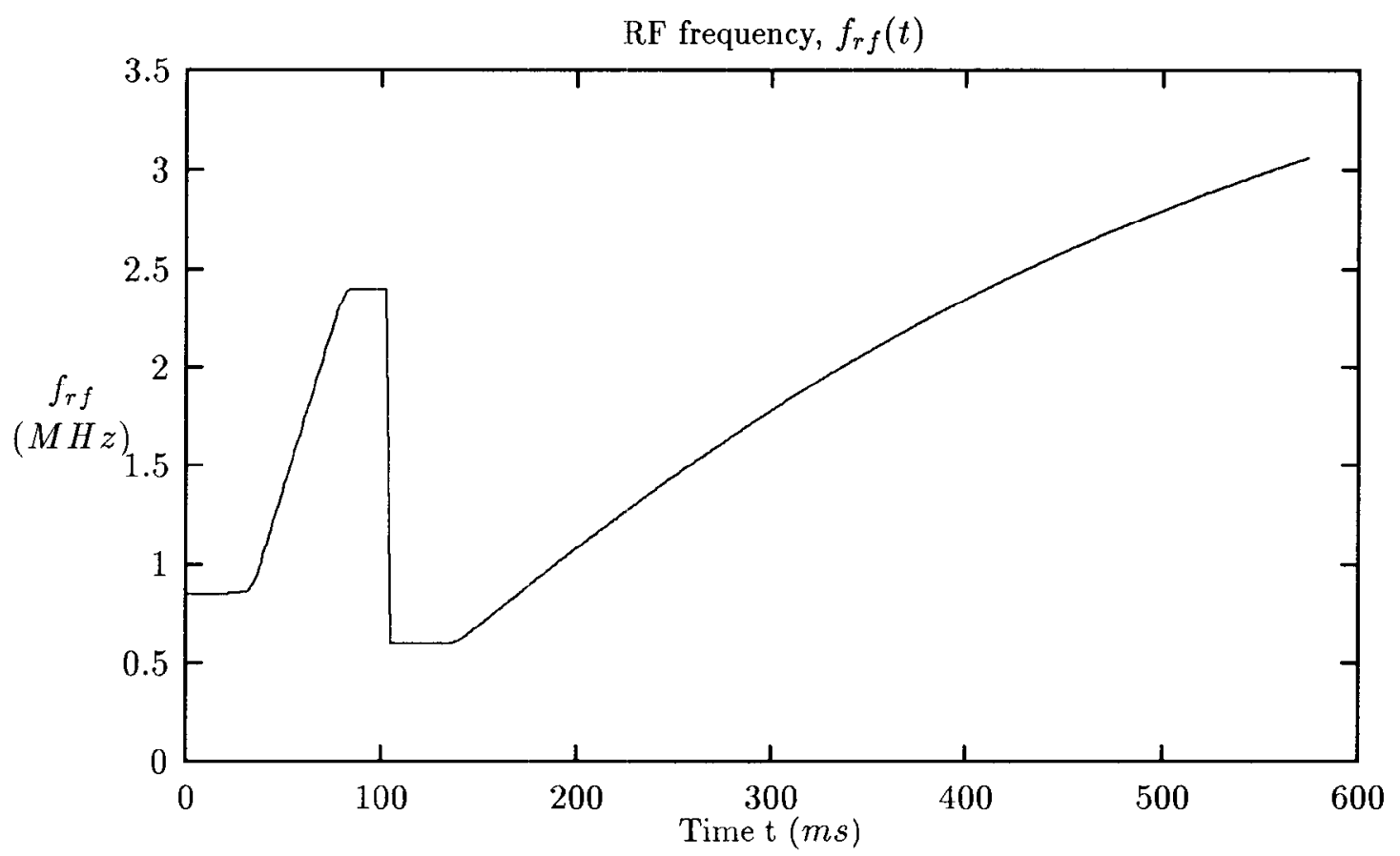

Figure 1: RF frequency vs. lime

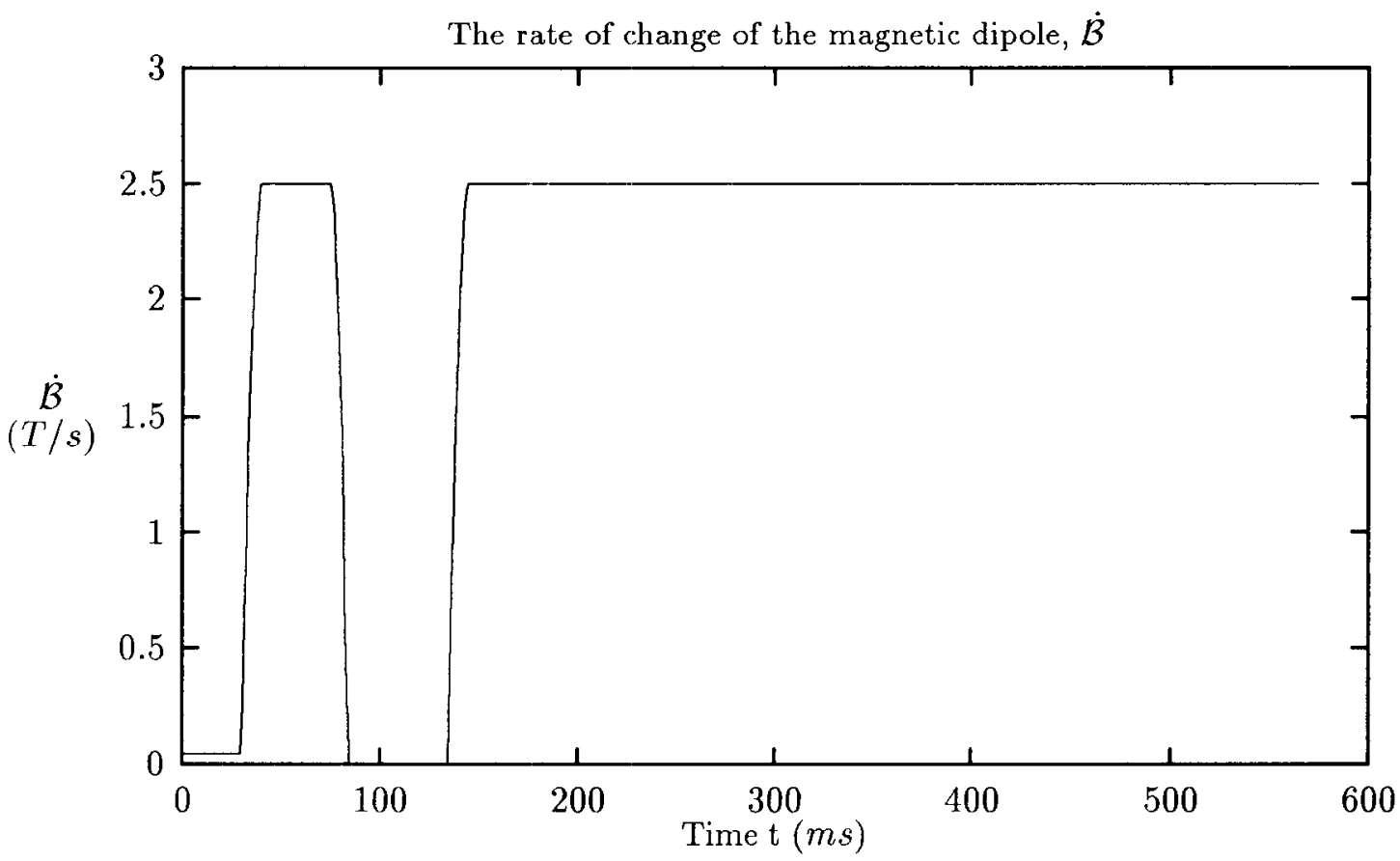

Figure 2: The rate of change of the magnetic dipole field vs. time. $A u^{+33}, h=12$. 


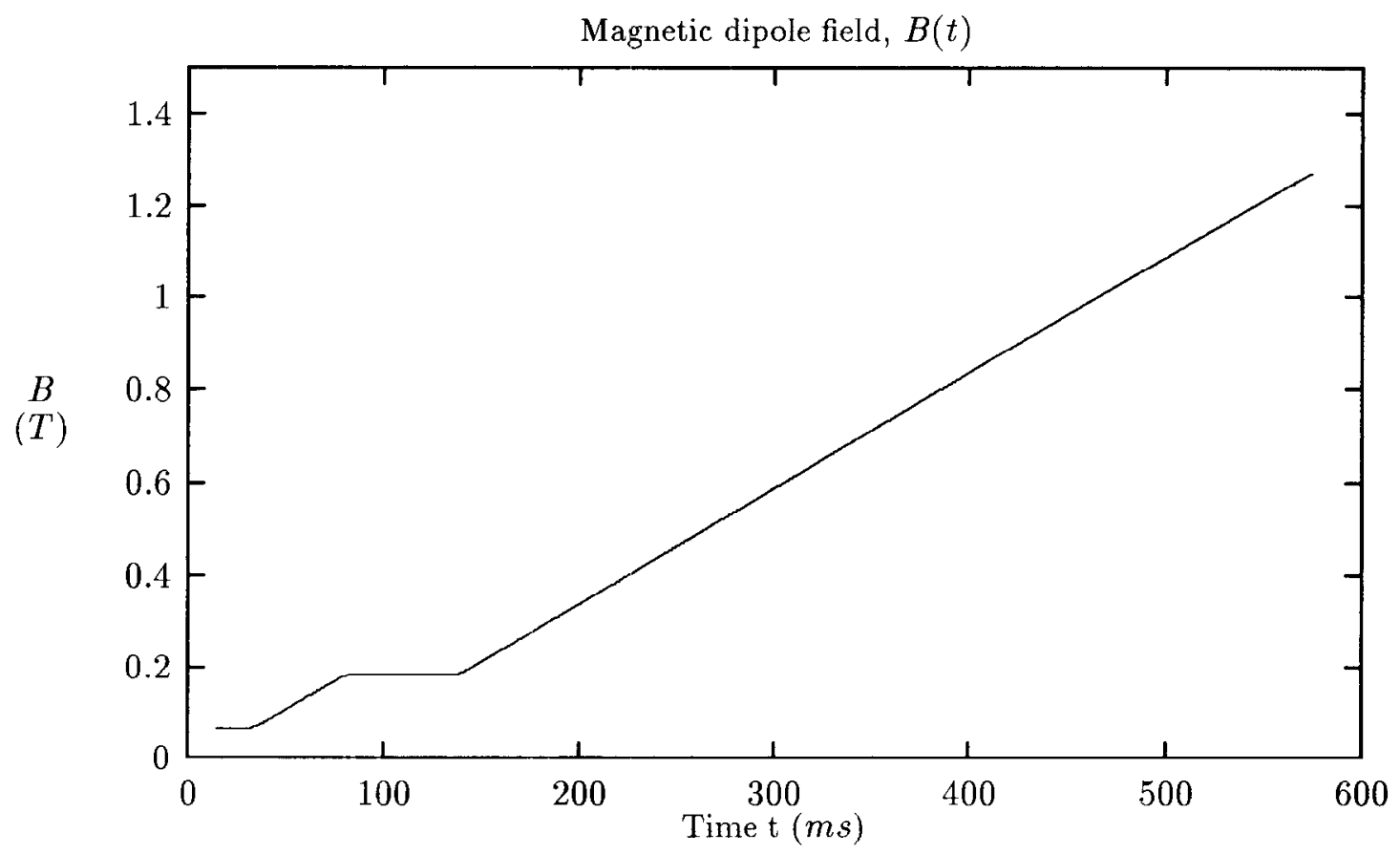

Figure 3: The magnetic dipole field vs. time. $A u^{+33}, h=12$.

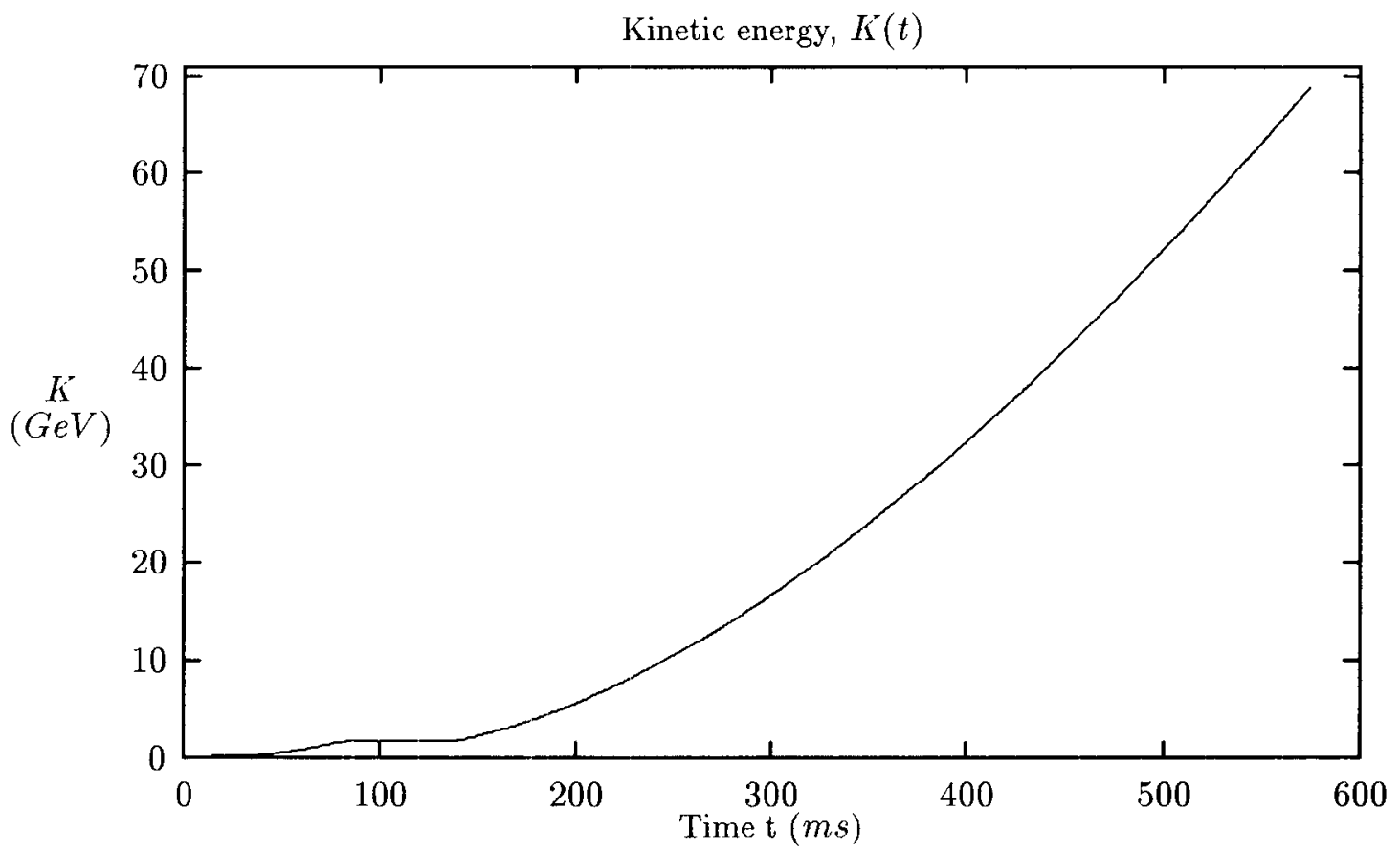

Figure 4: Kinetic energy vs. time. $A u^{+33}, h=12$. 


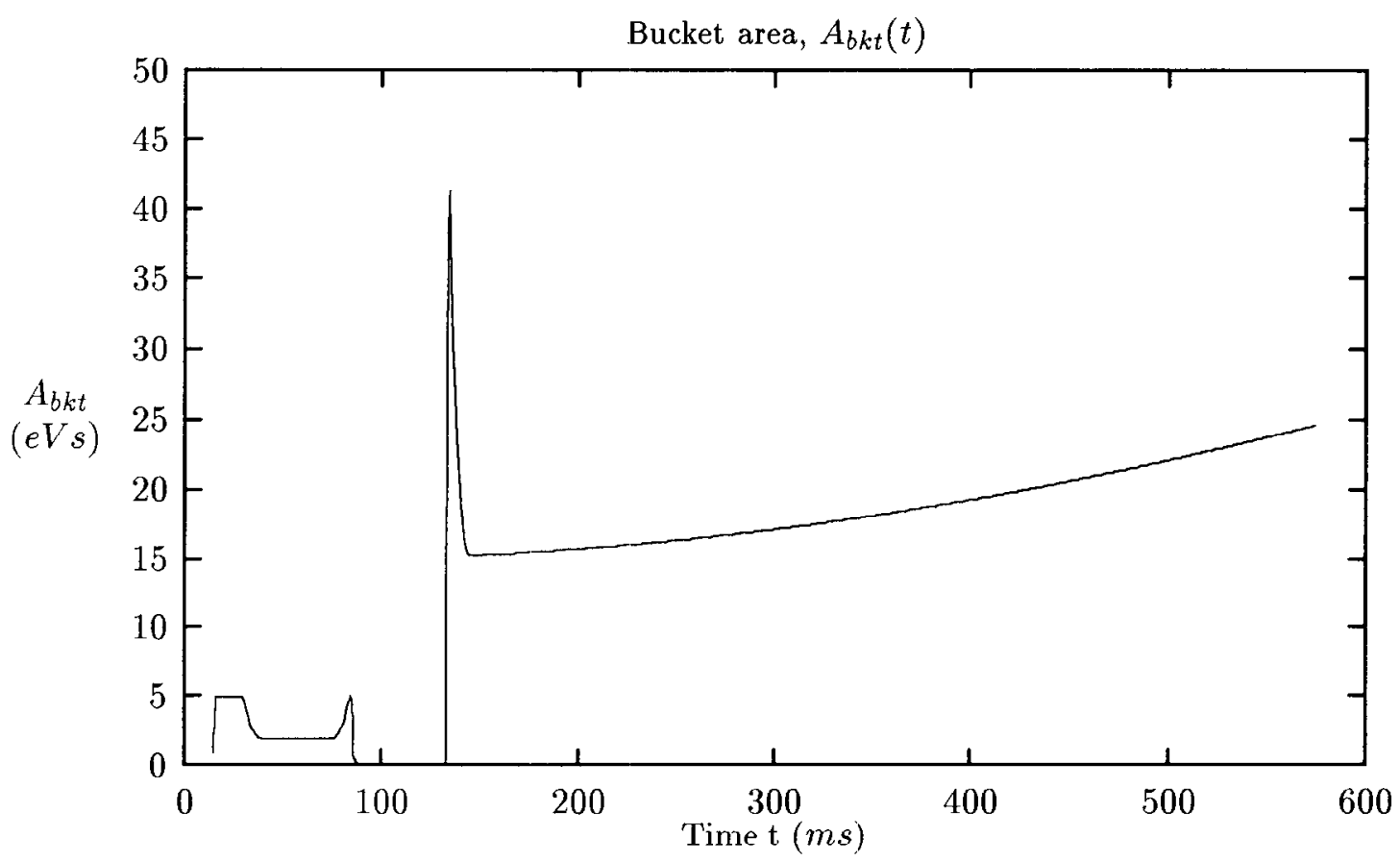

Figure 5: The bucket area vs. time. $A u^{+33}, h=12$.

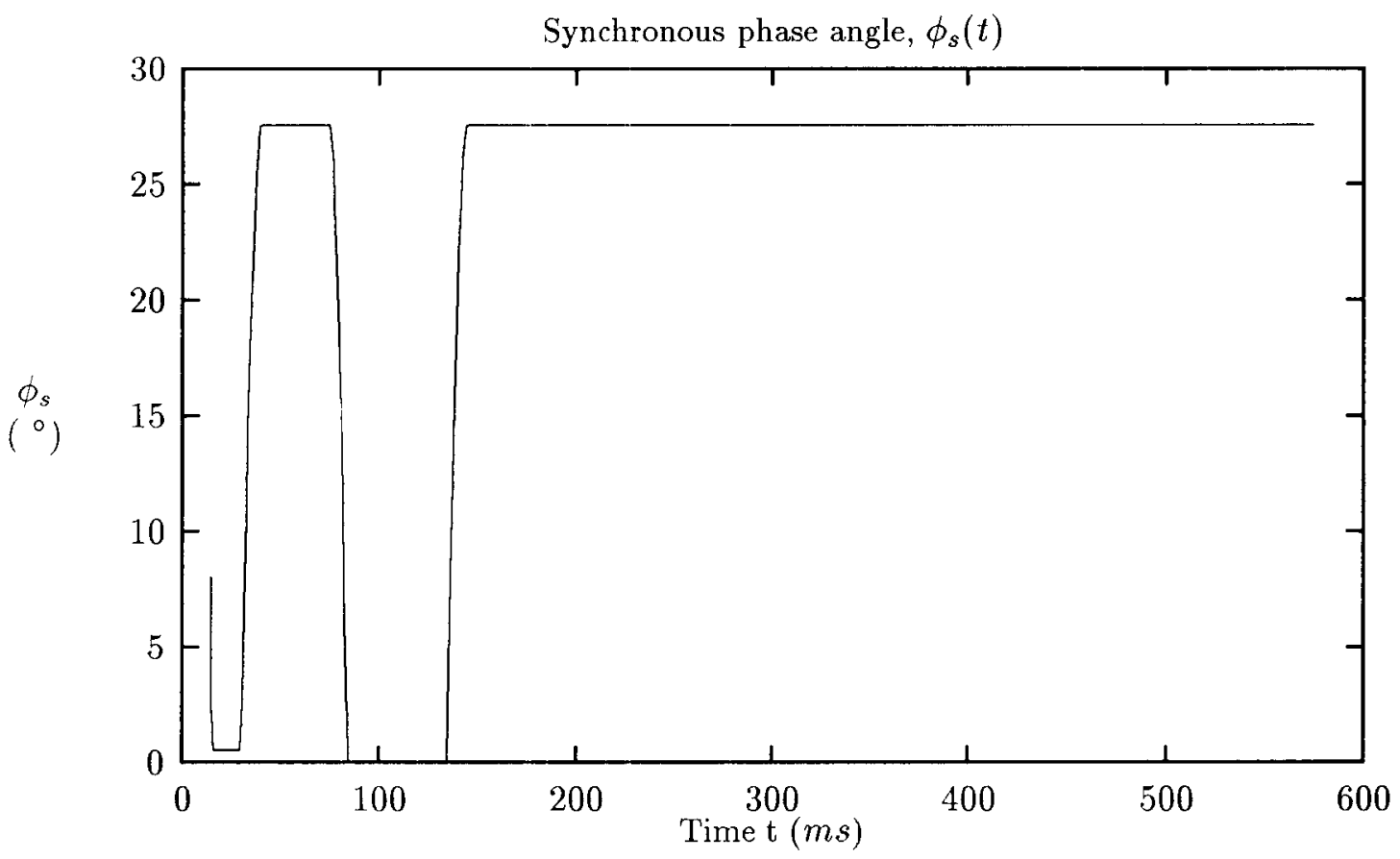

Figure 6: Synchronous phase angle vs. time. $A u^{+33}, h=12$. 


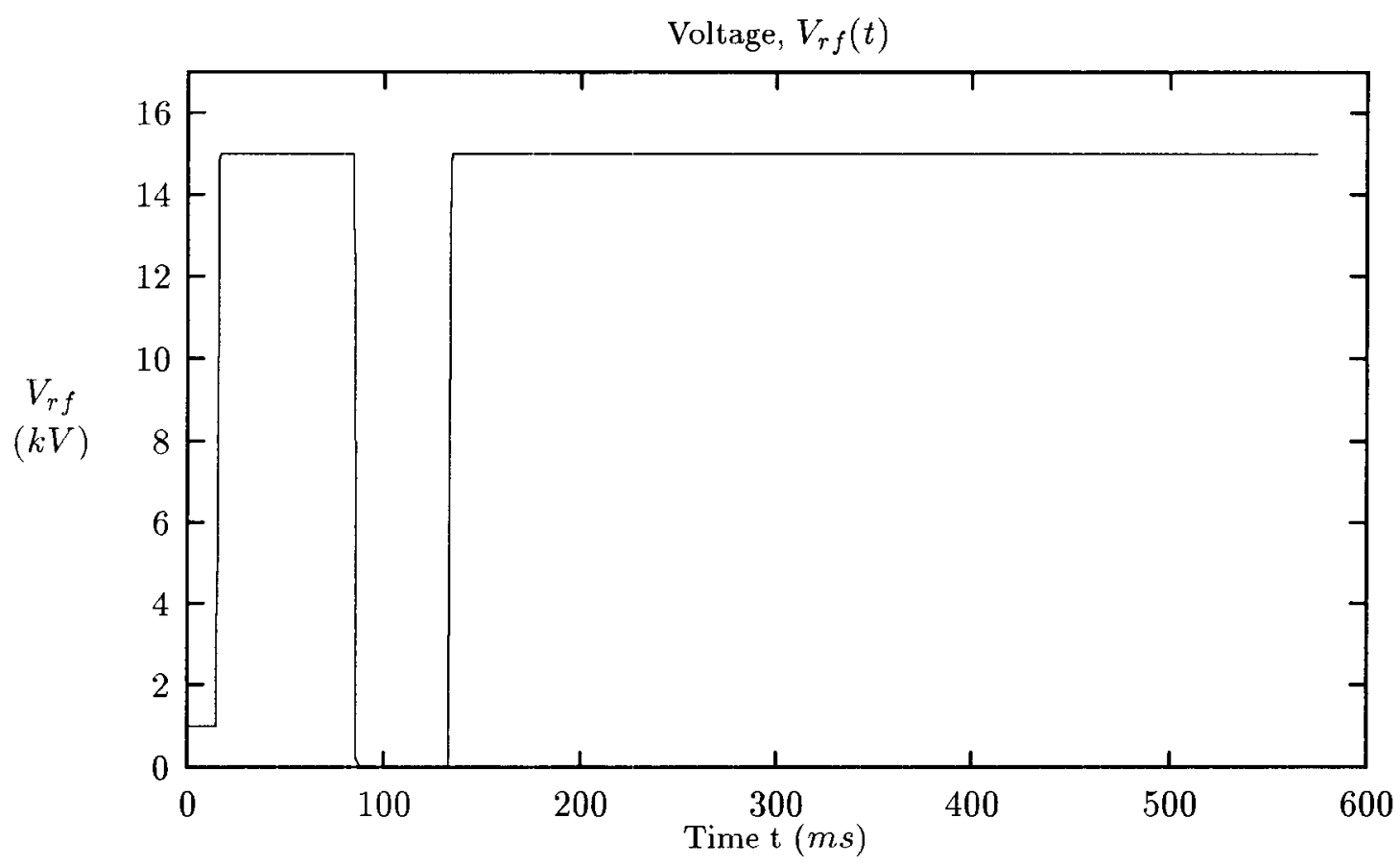

Figure 7: RF voltage vs. time. $A u^{+33}, h=12$.

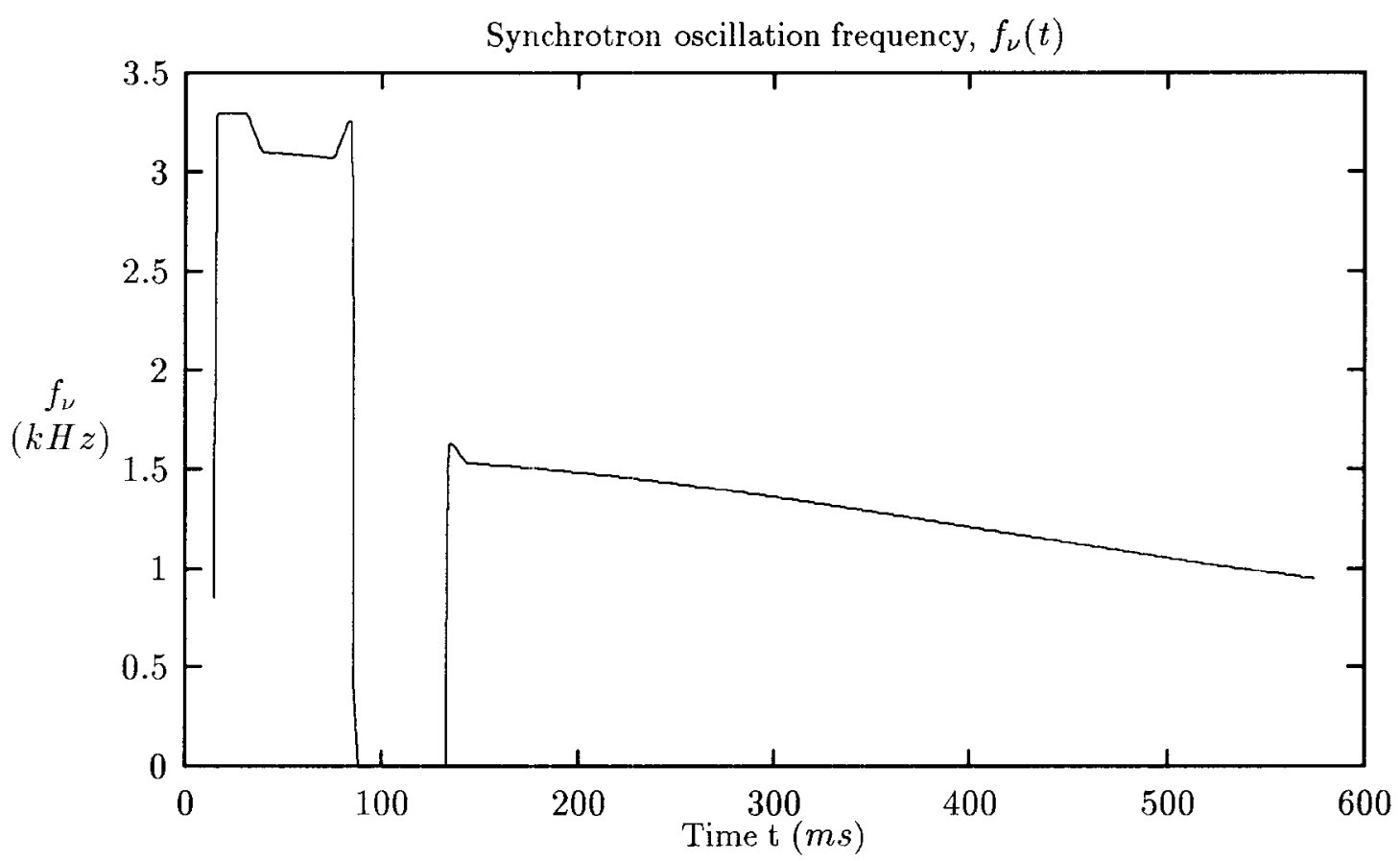

Figure 8: Synchrotron oscillation frequency vs. time. $A u^{+33}, h=12$. 


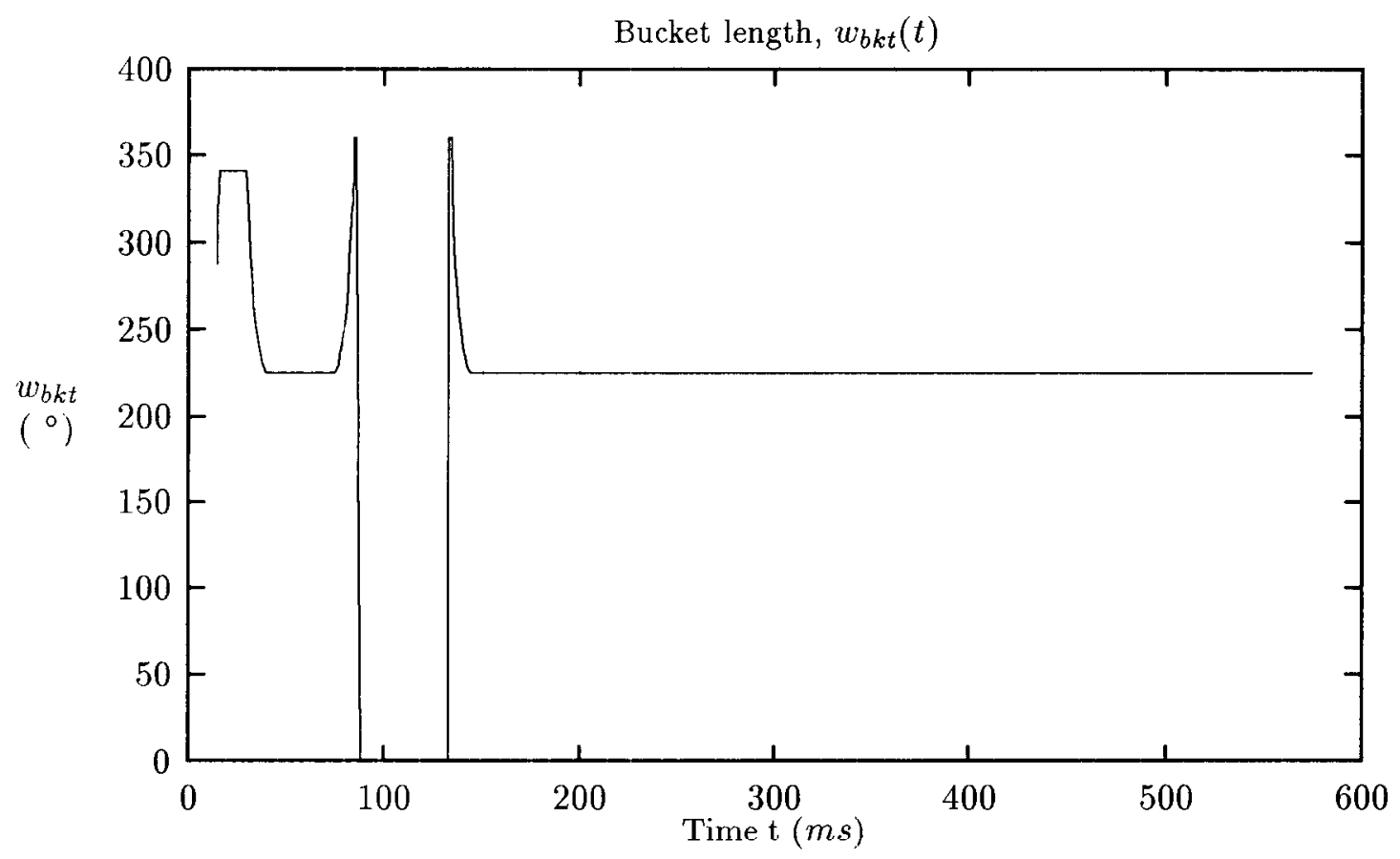

Figure 9: Bucket length (degree) vs. time. $A u^{+33}, h=12$.

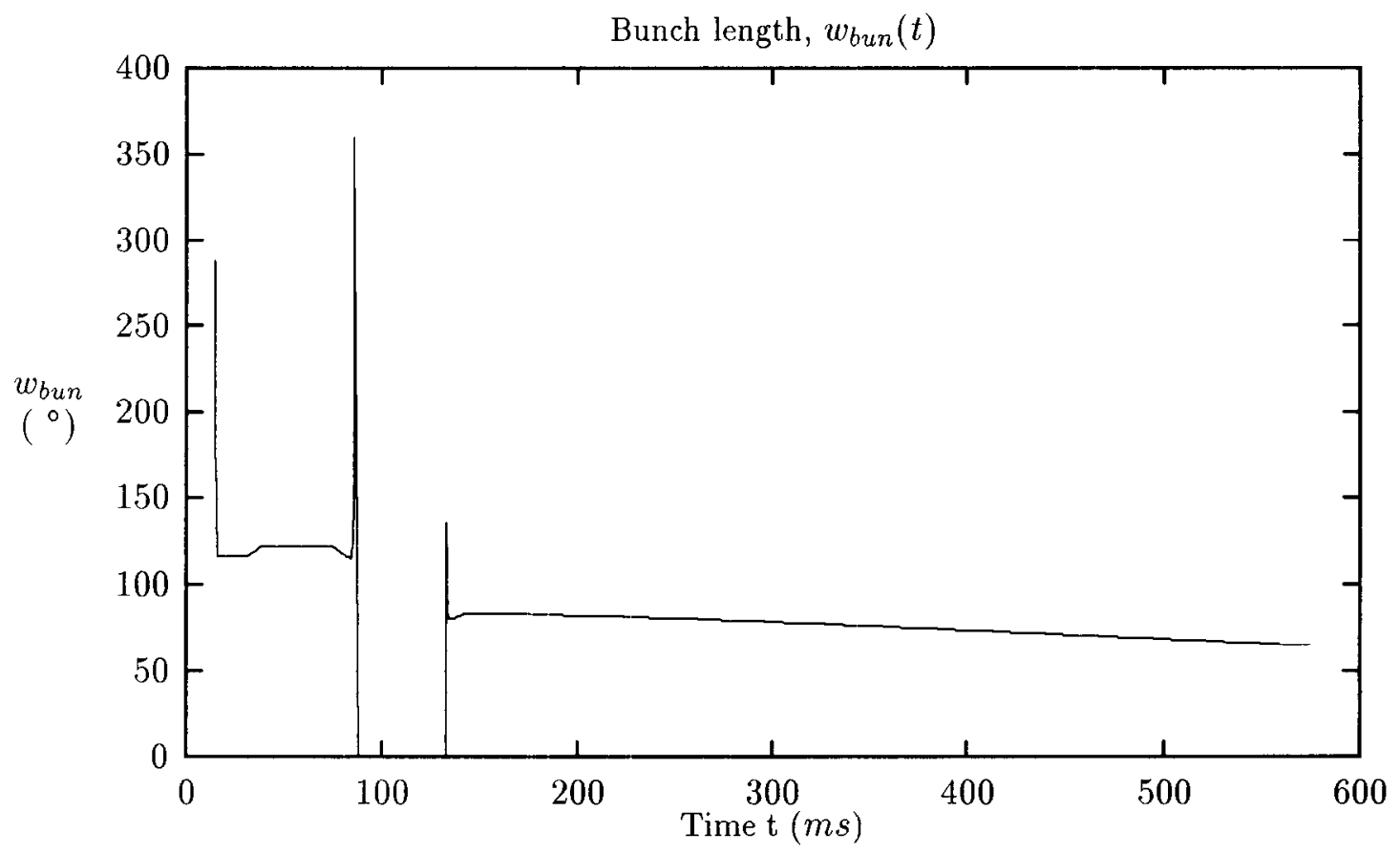

Figure 10: Bunch length (degree) vs. time. $A u^{+33}, h=12$. 


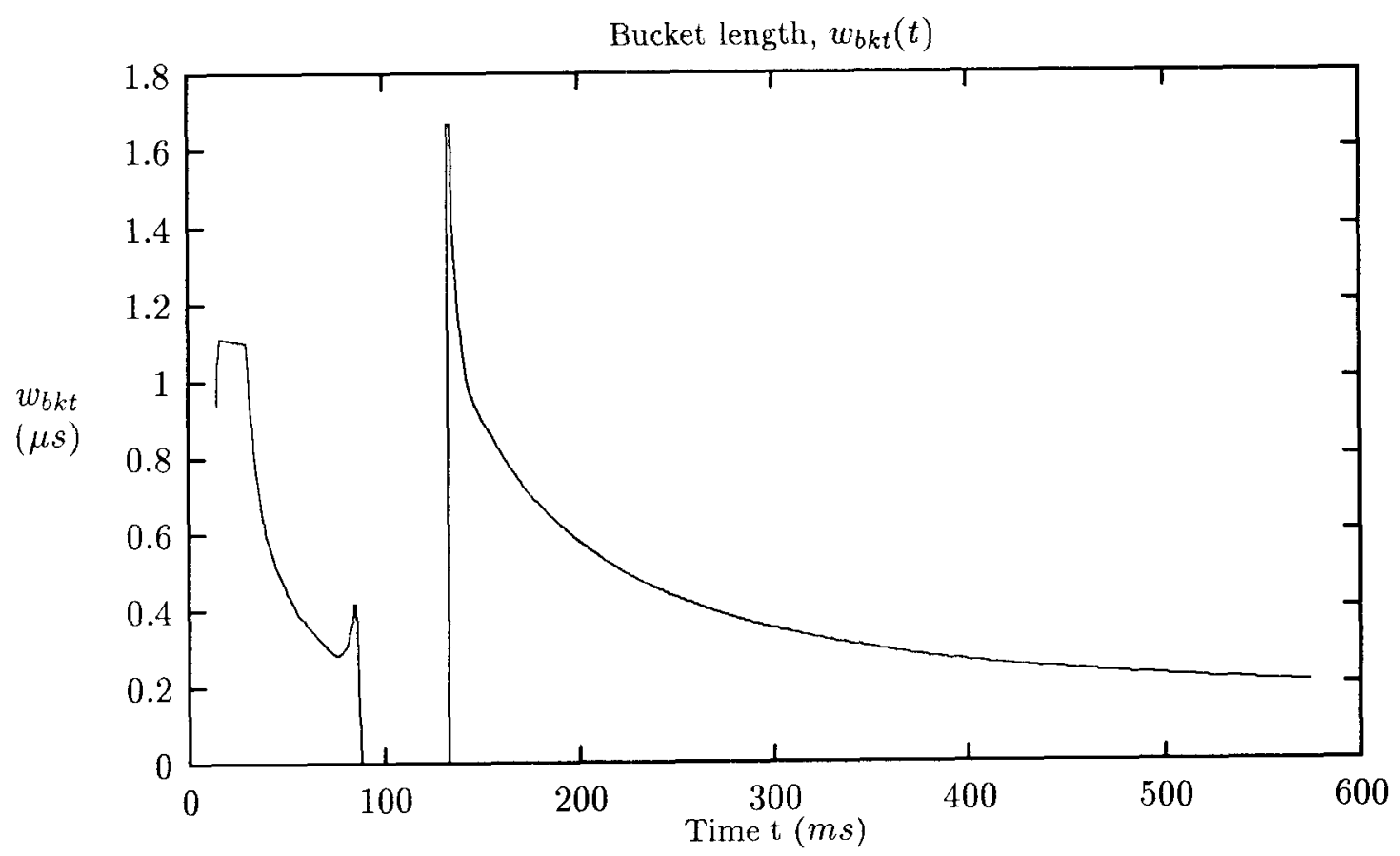

Figure 11: Bucket, length (ms) vs. time. $A u^{+33}, h=12$.

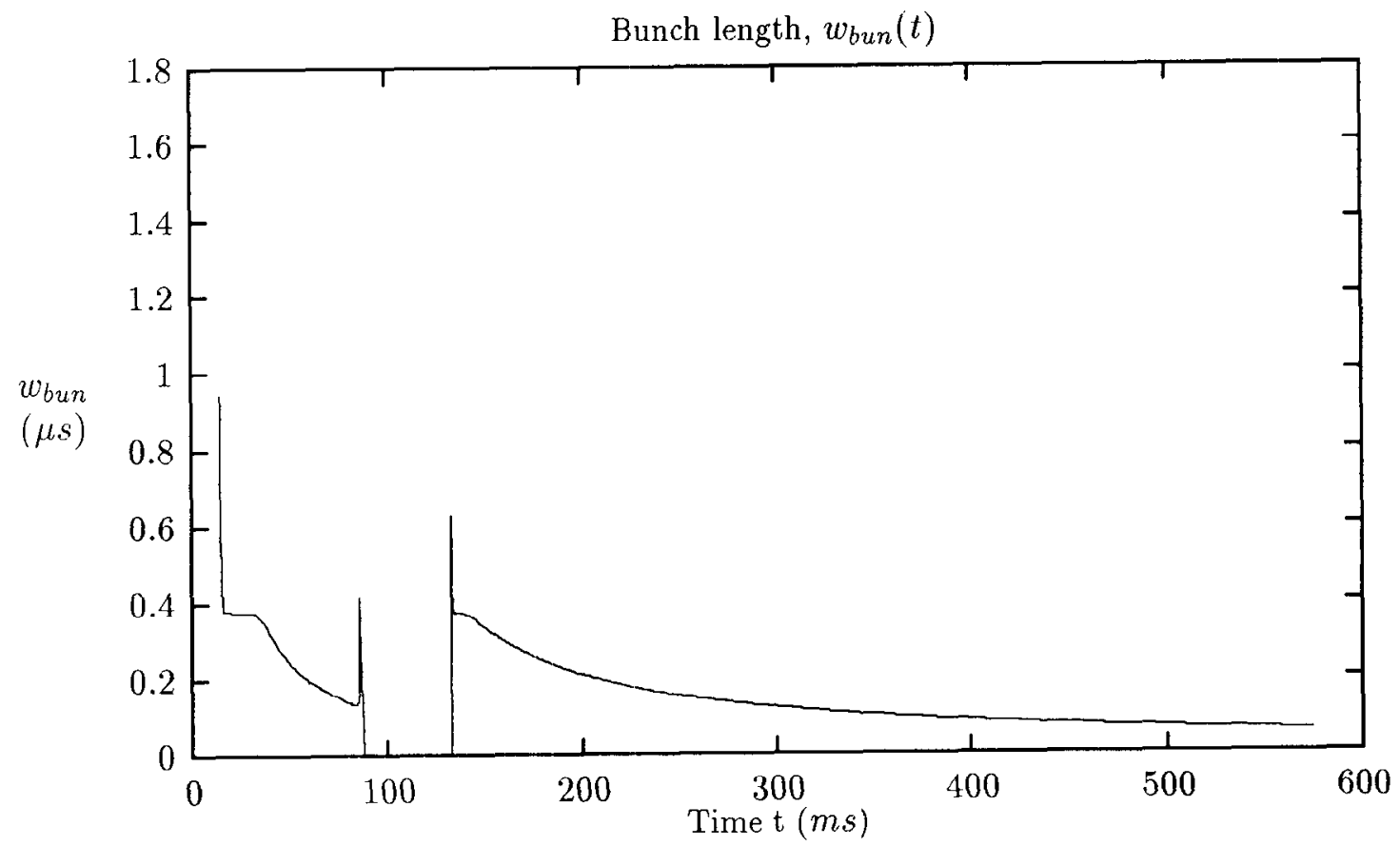

Figure 12: Bunch length (ms) vs. time. $A u^{+33}, h=12$. 


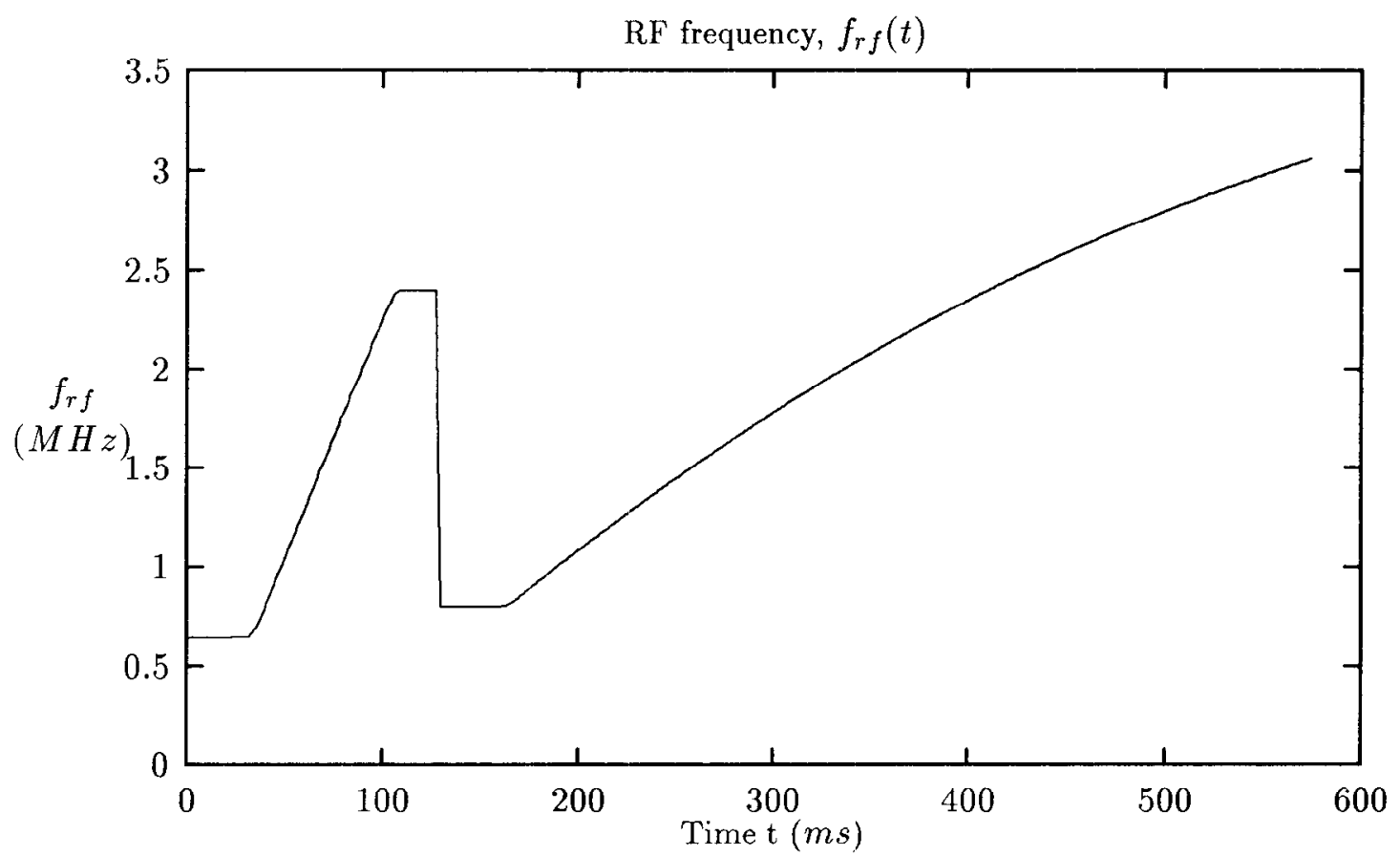

Figure 13: RF frequency vs. lime. $A u^{+33}, h=9$.

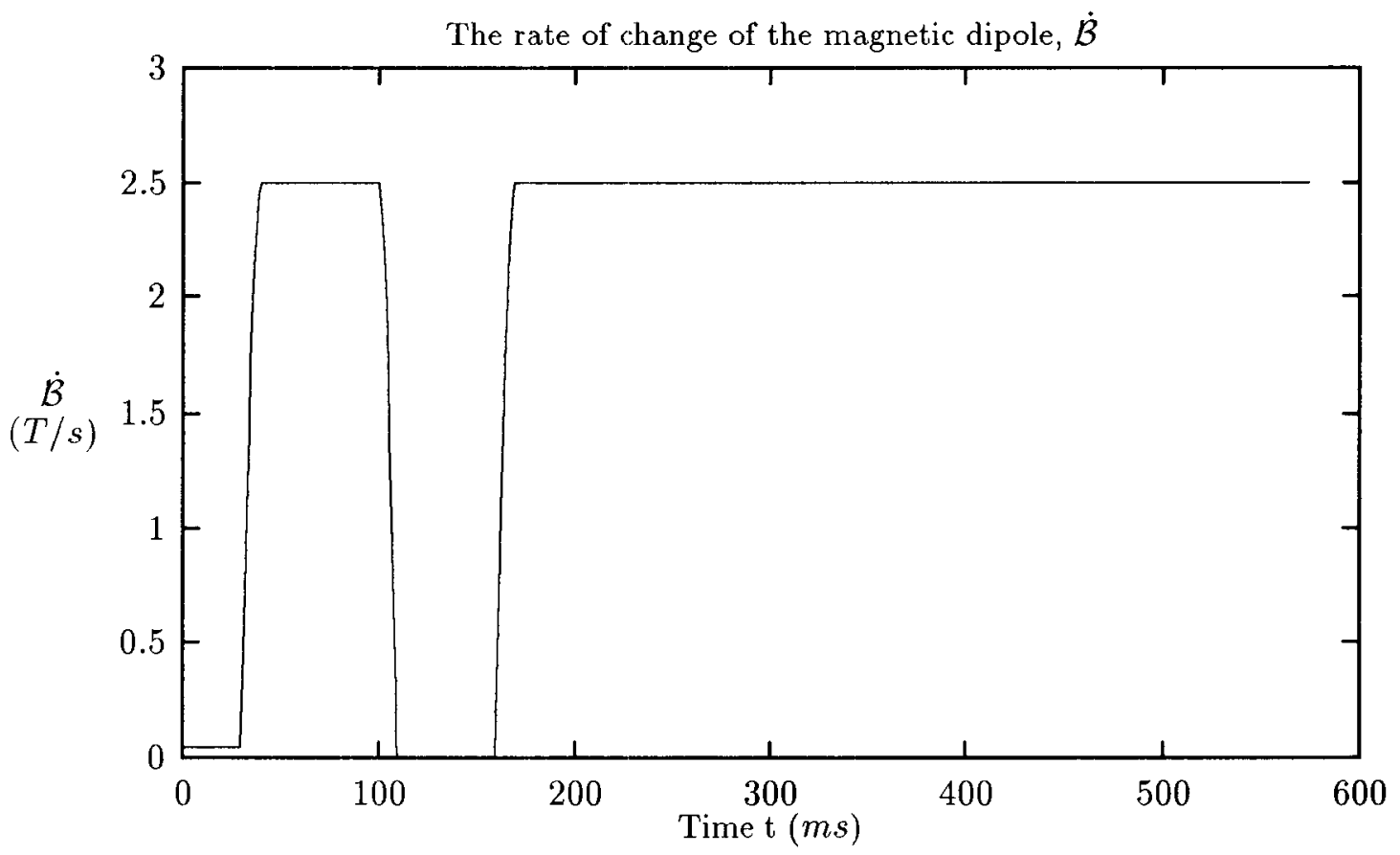

Figure 14: The rate of change of the magnetic dipole field vs. time. $A u^{+33}, h=9$. 


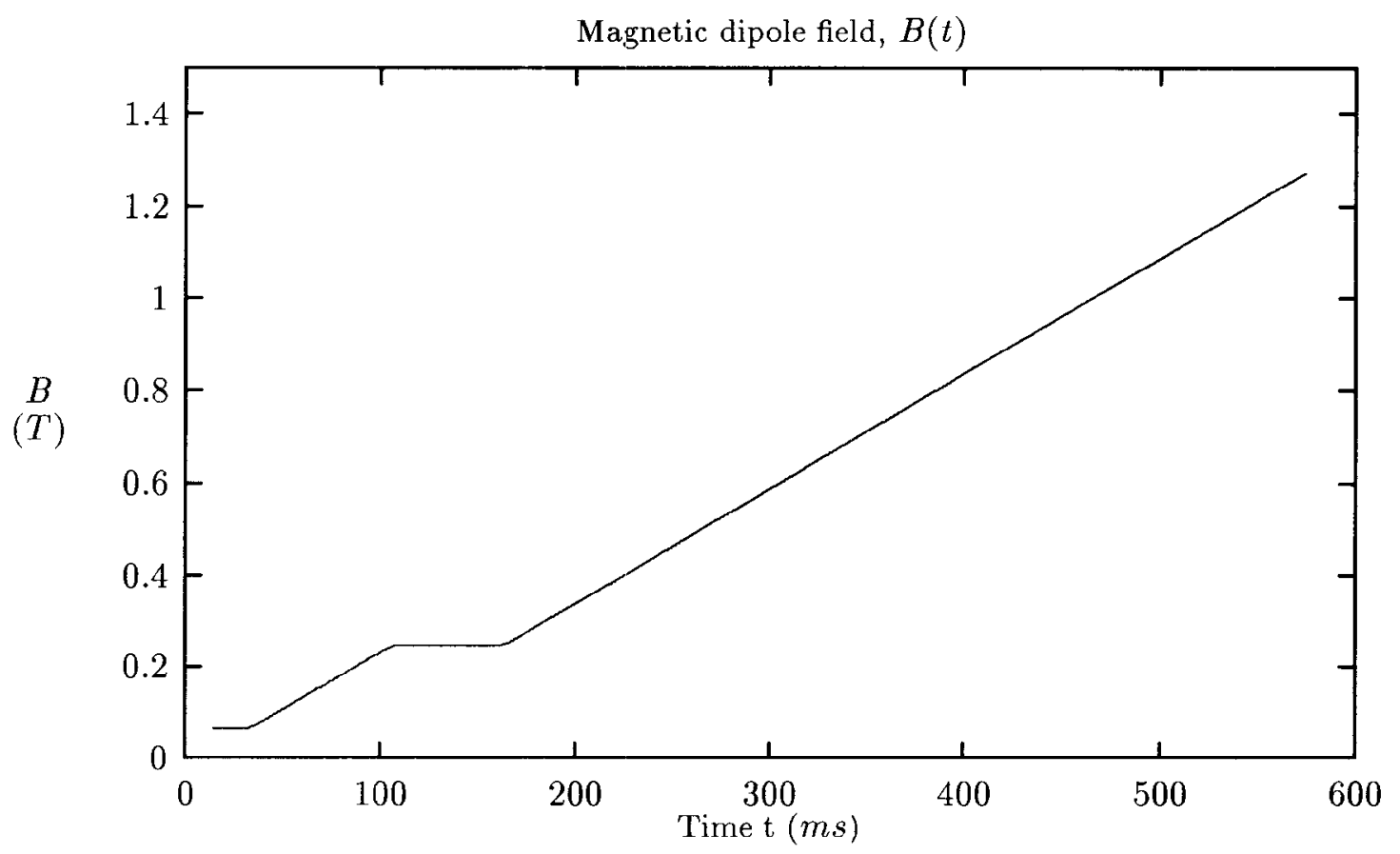

Figure 15: The magnetic dipole field vs. time. $A u^{+33}, h=9$.

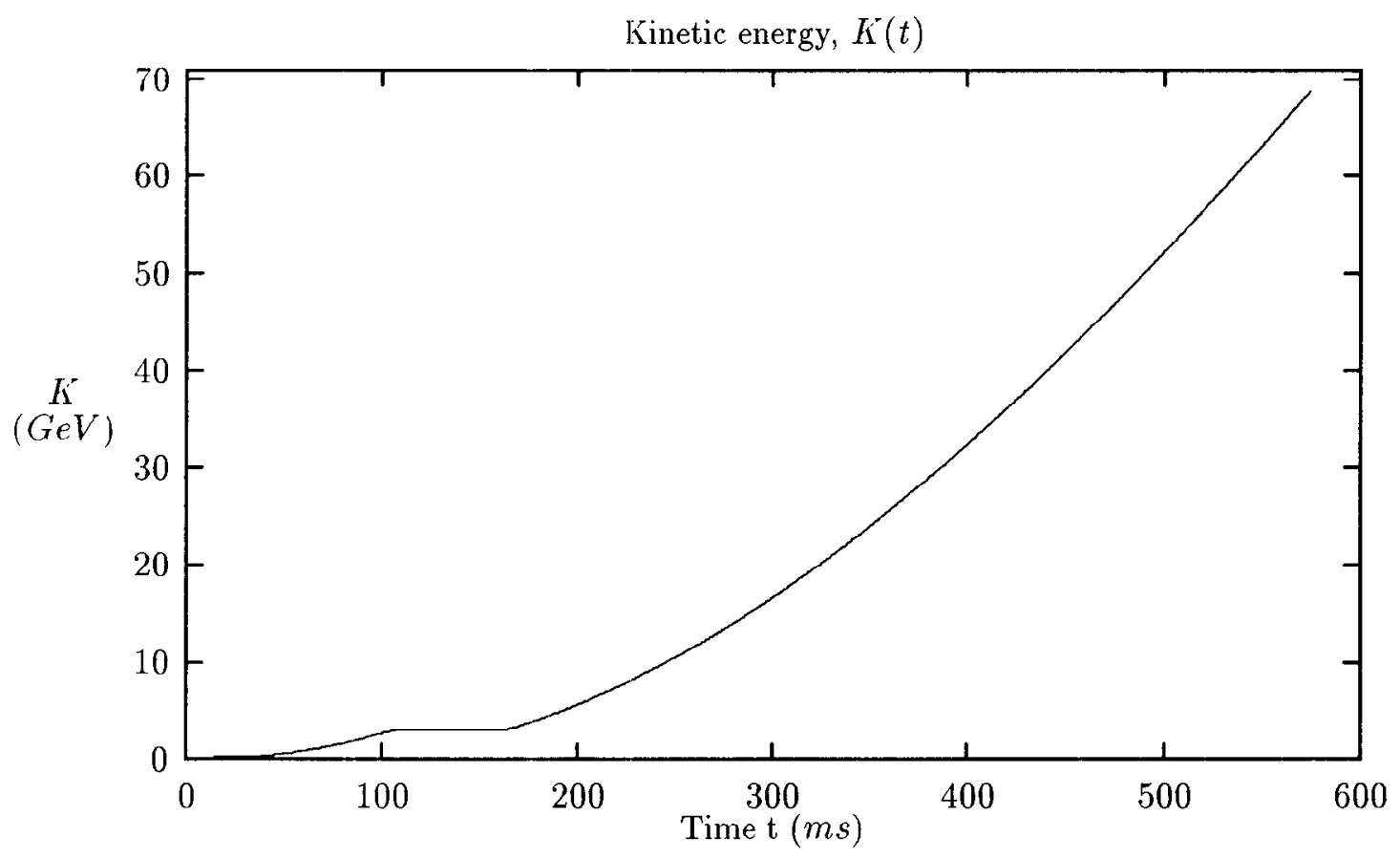

Figure 16: Kinetic energy vs. time. $A u^{+33}, h=9$. 


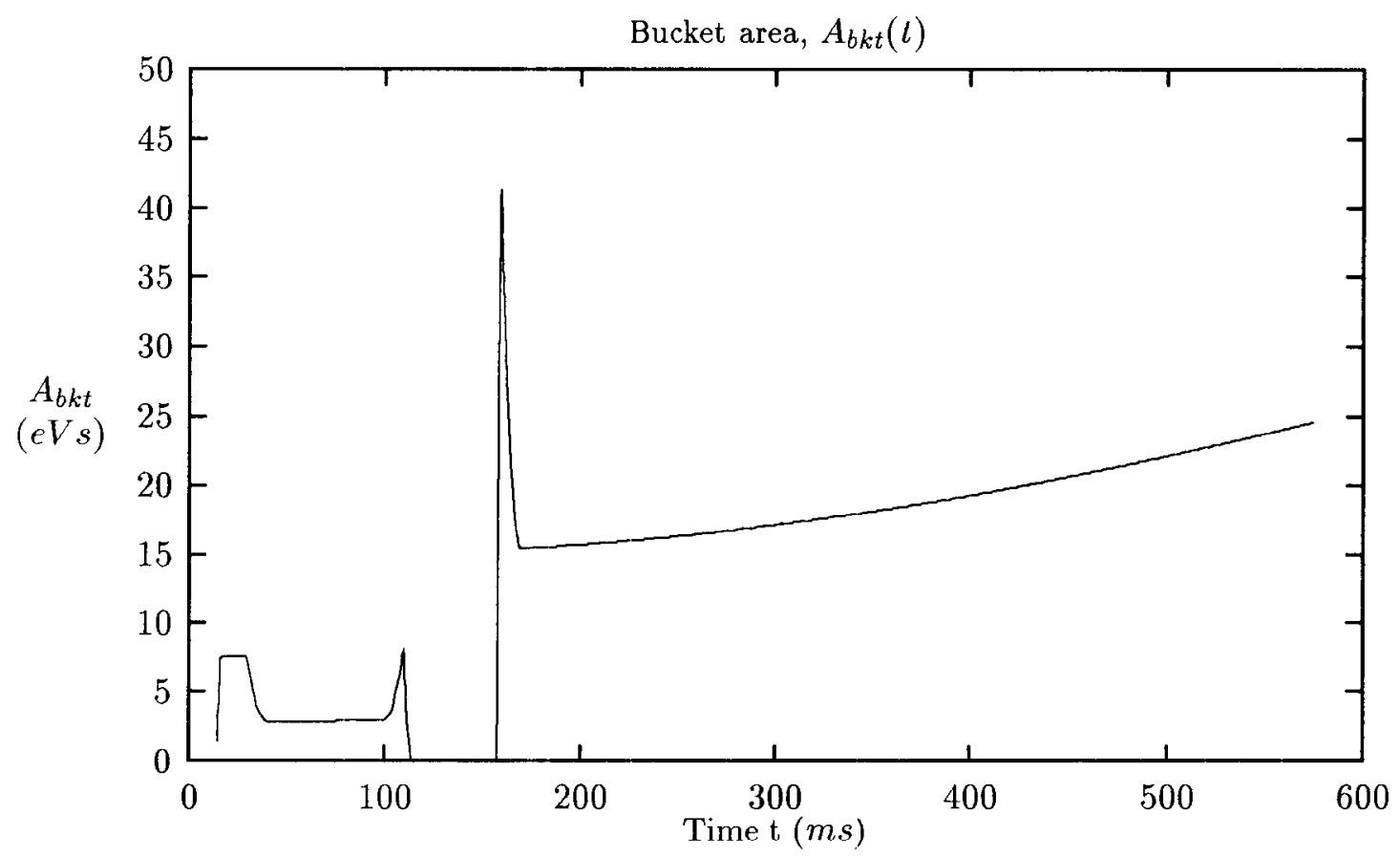

Figure 17: The bucket area vs. time. $A u^{+33}, h=9$.

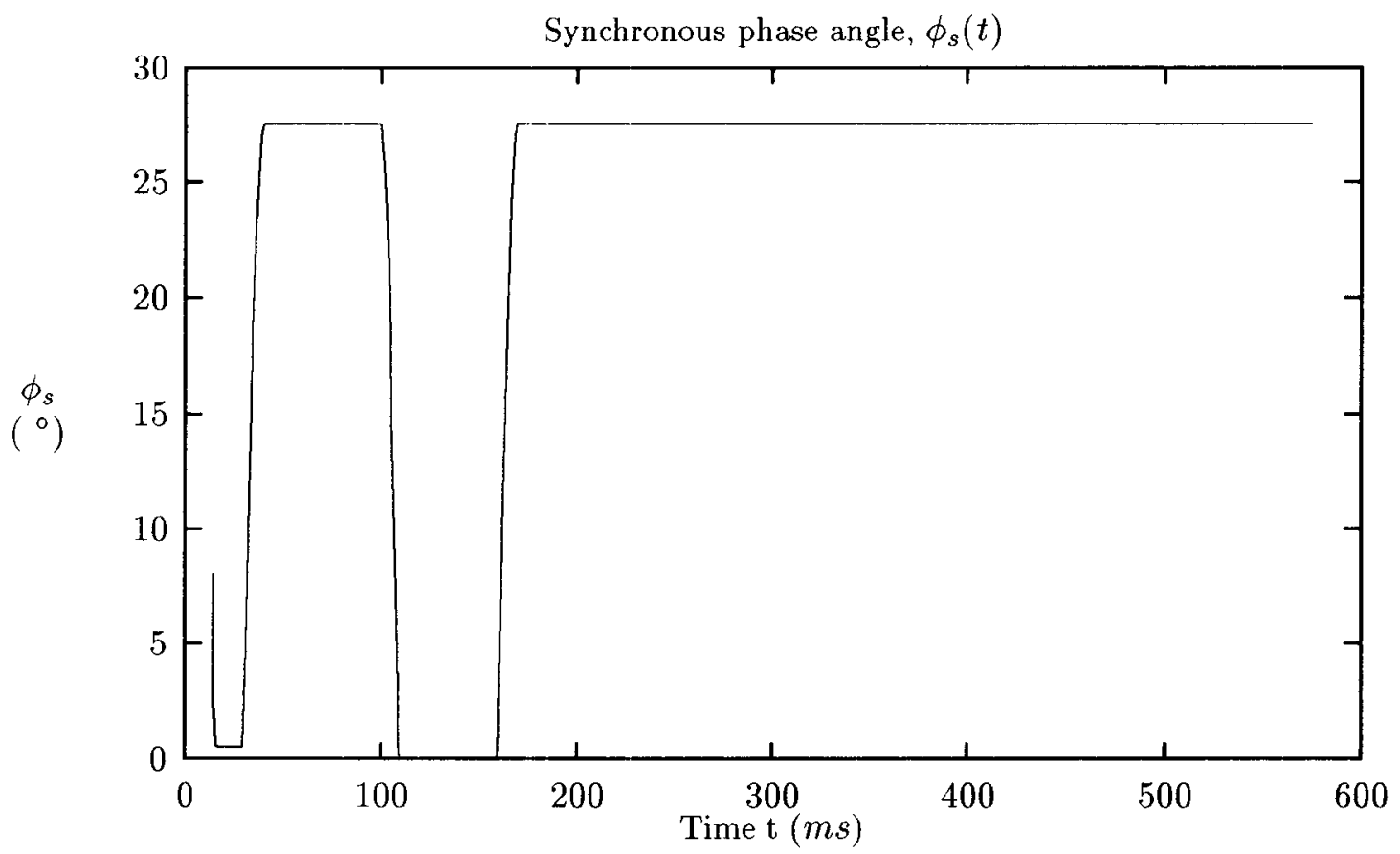

Figure 18: Synchronous phase angle vs. time. $A u^{+33}, h=9$. 


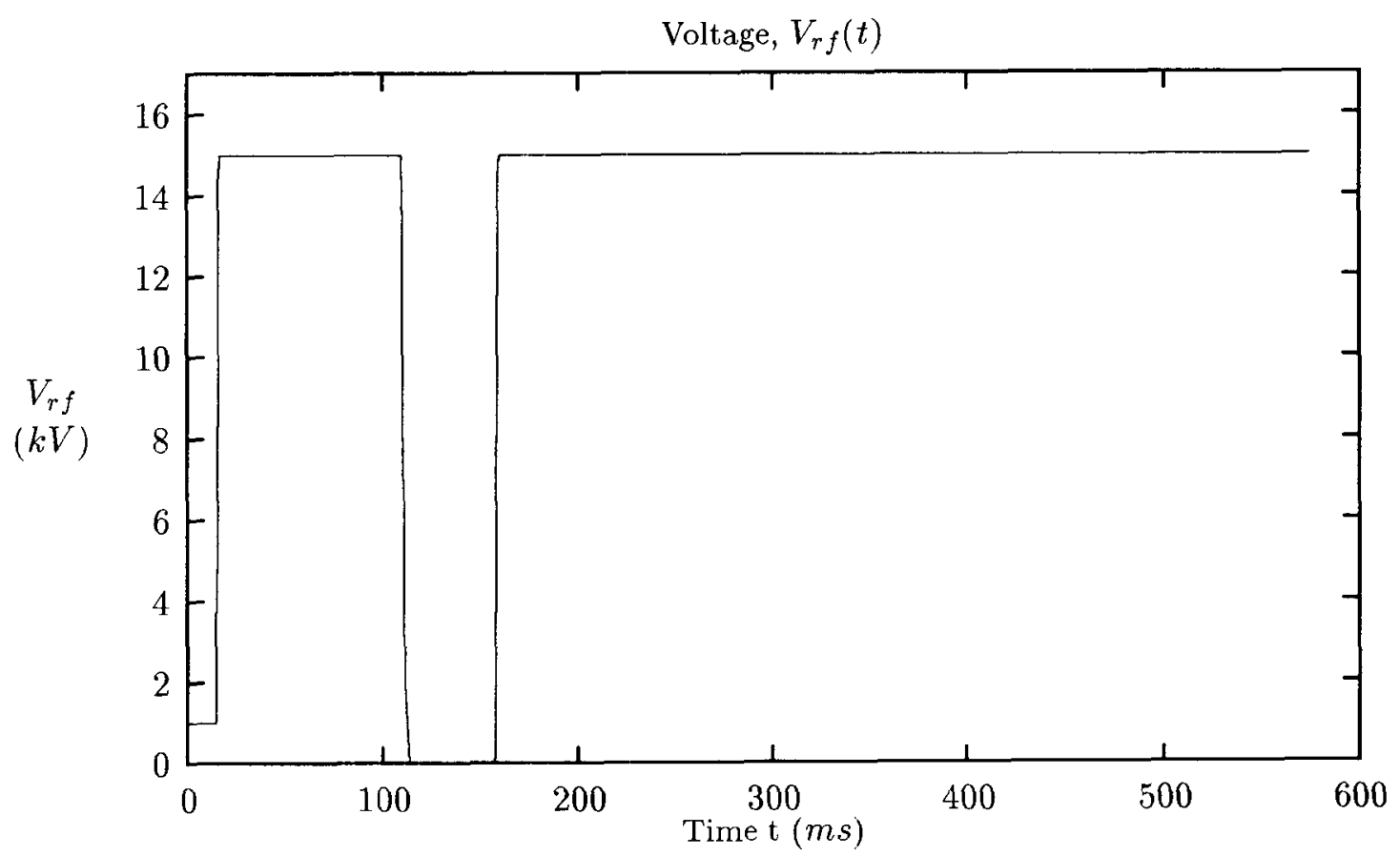

Figure 19: RF voltage vs. time. $A u^{+33}, h=9$.

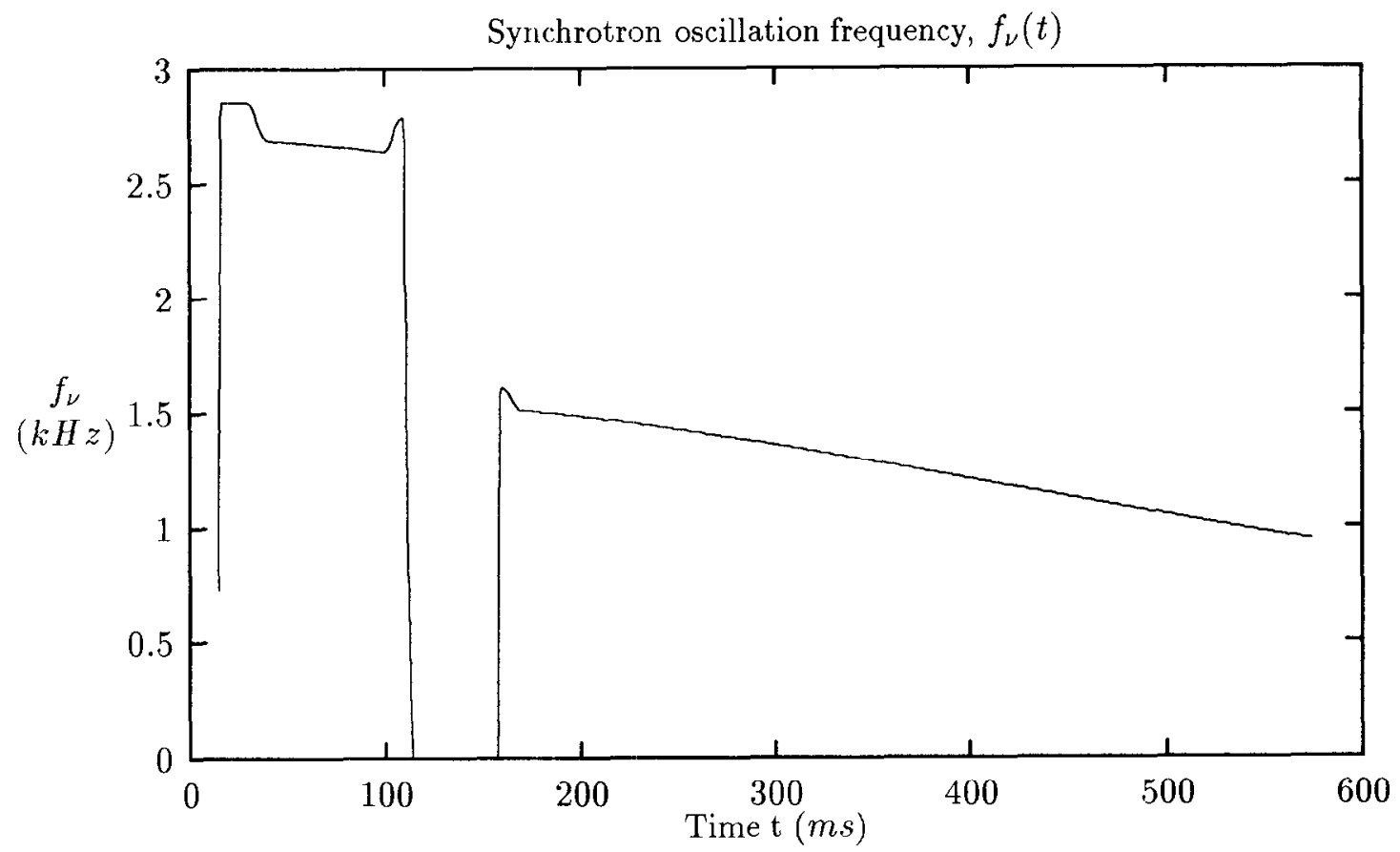

Figure 20: Synchrotron oscillation frequency vs. time. $A u^{+33}, h=9$. 


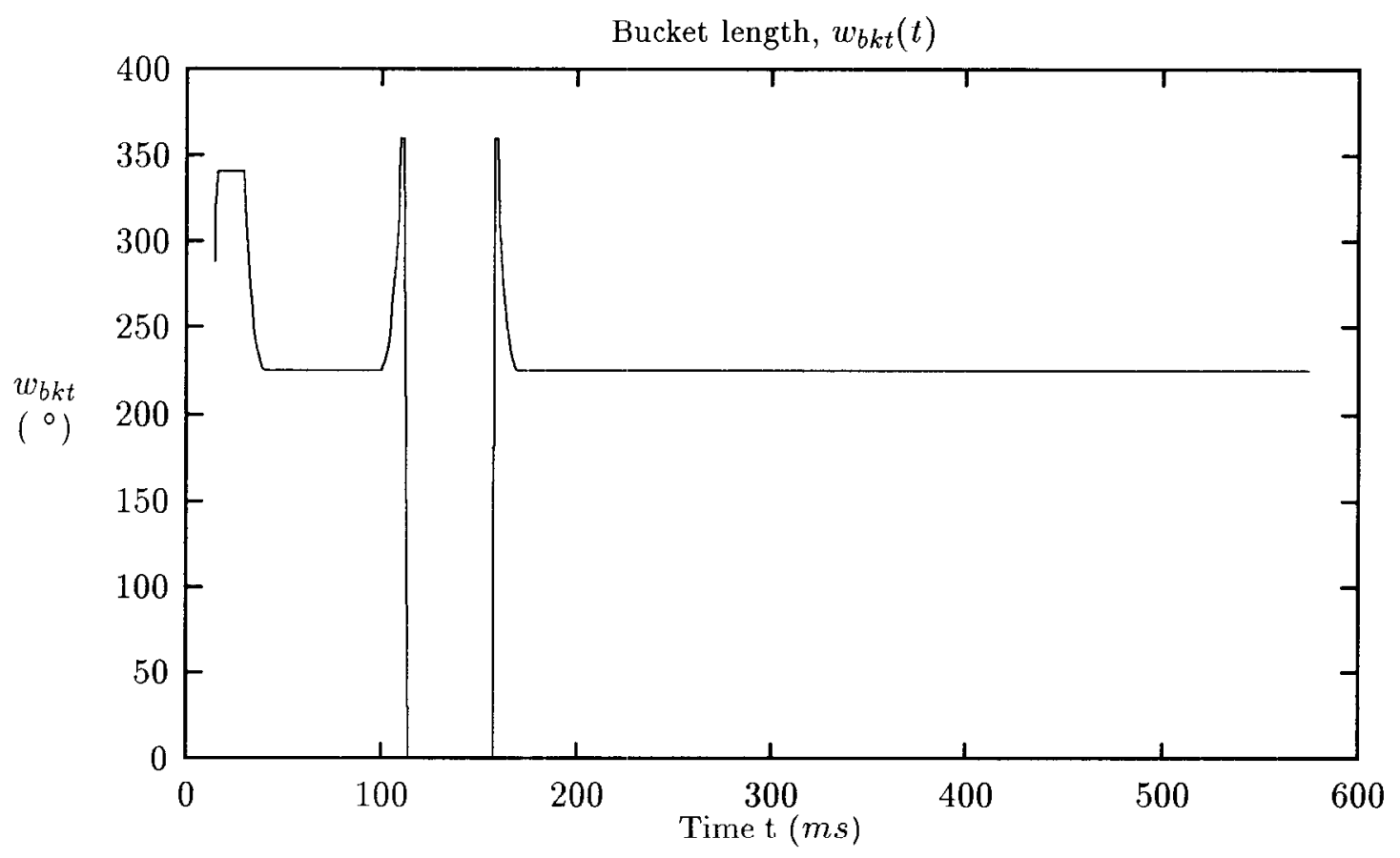

Figure 21: Bucket length (degree) vs. time. $A u^{+33}, h=9$.

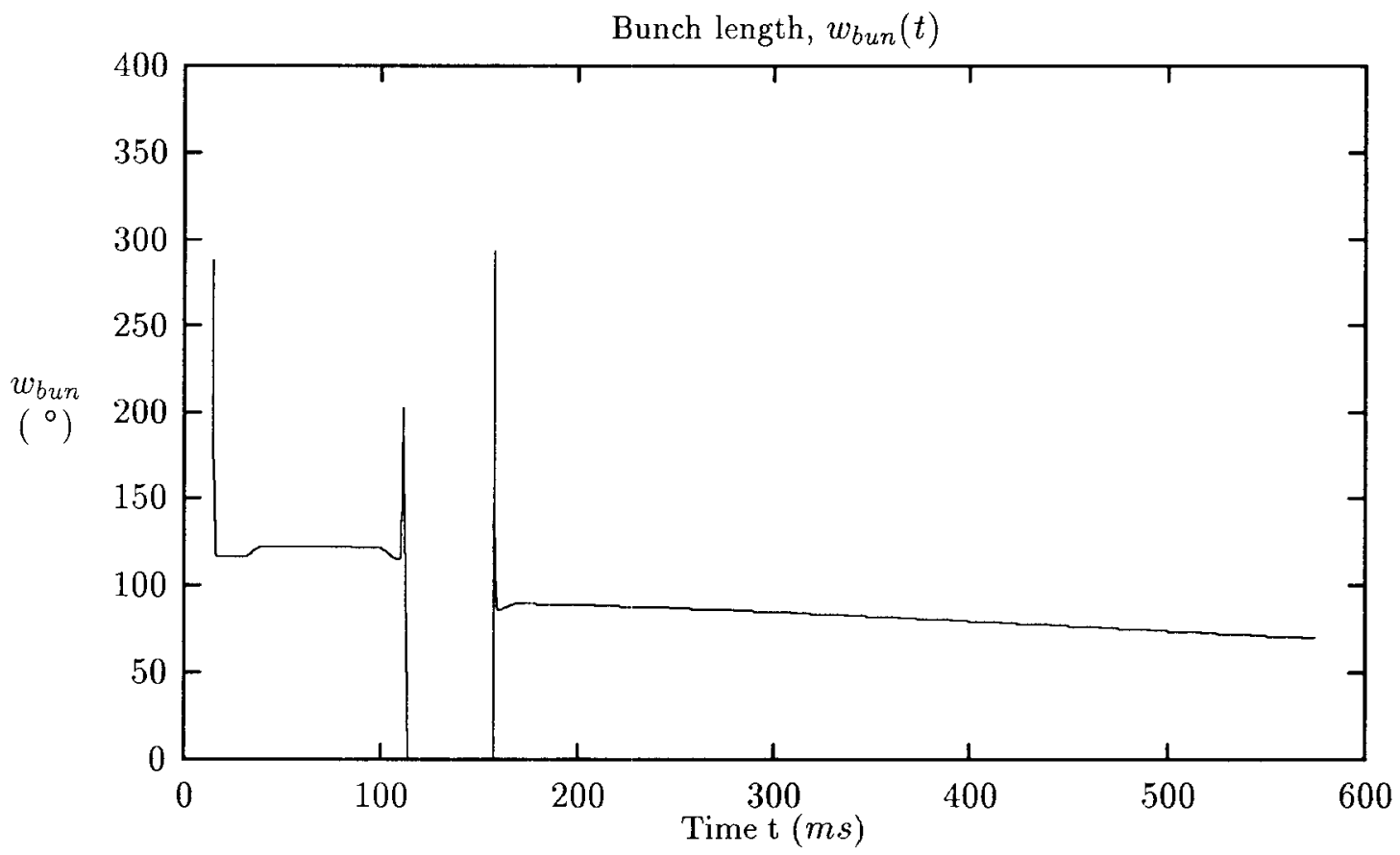

Figure 22: Bunch length (degree) vs. time. $A u^{+33}, h=9$. 


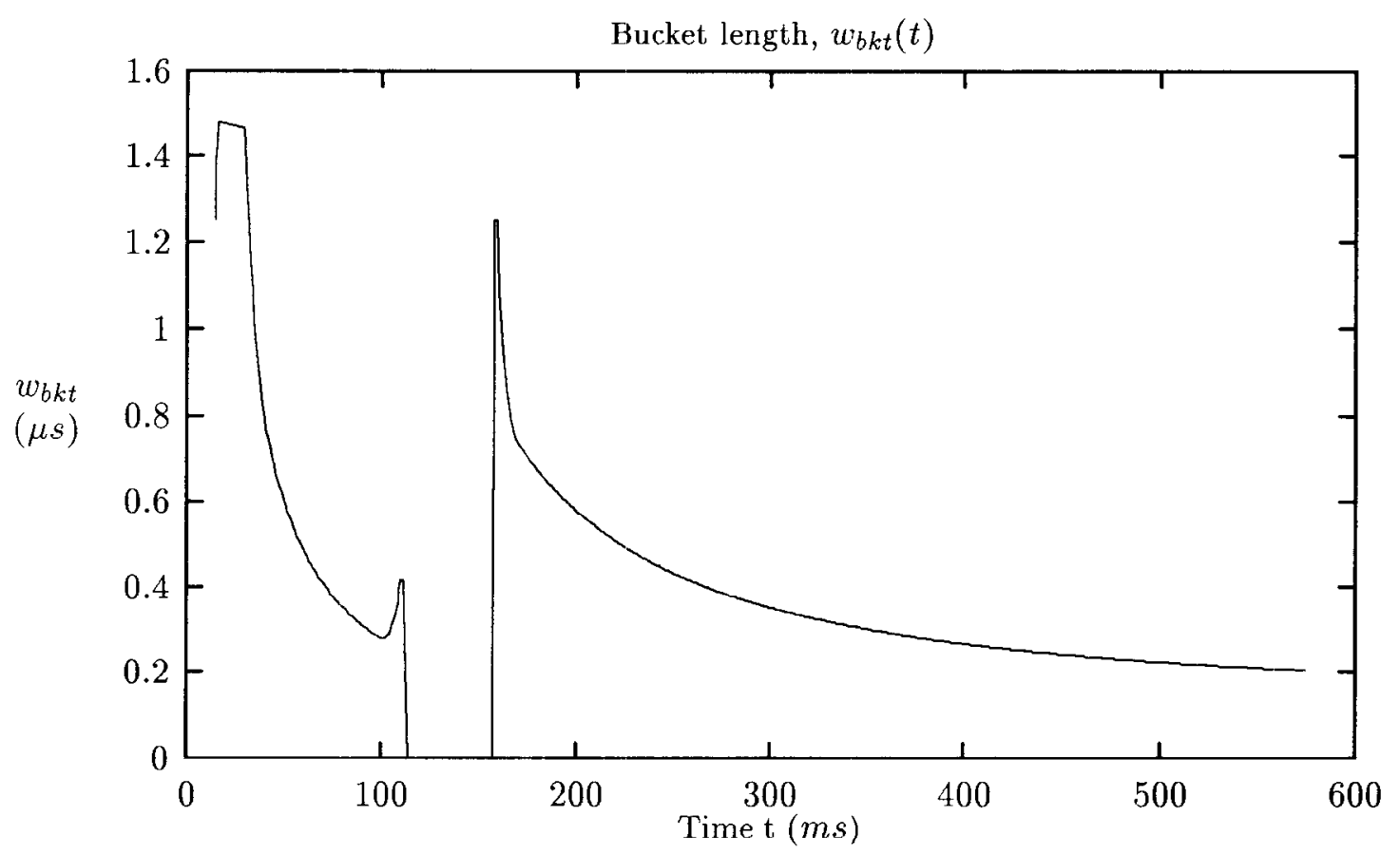

Figure 23: Bucket length $(m s)$ vs. time. $A u^{+33}, h=9$.

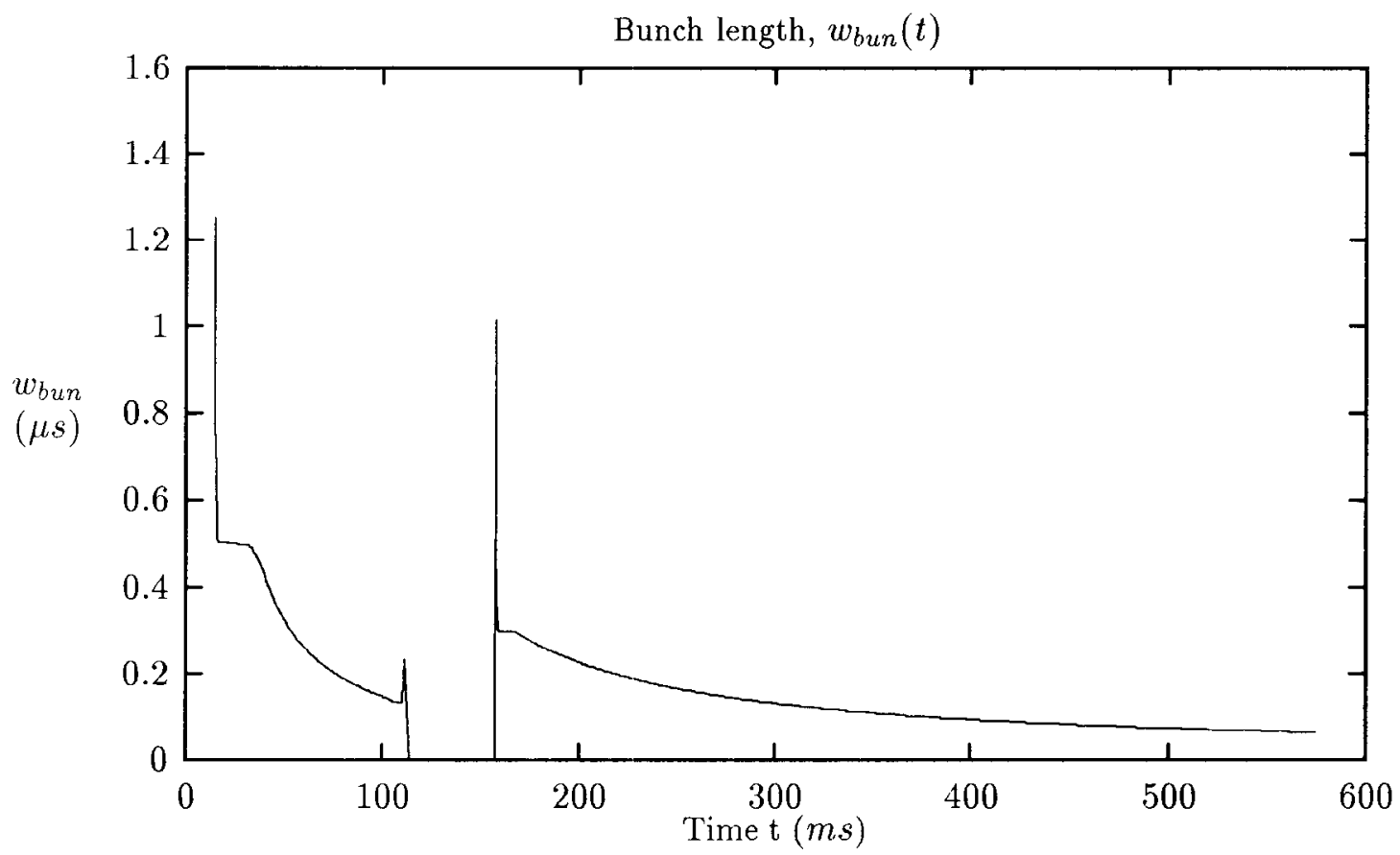

Figure 24: Bunclı length (ms) vs. time. $A u^{+33}, h=9$. 


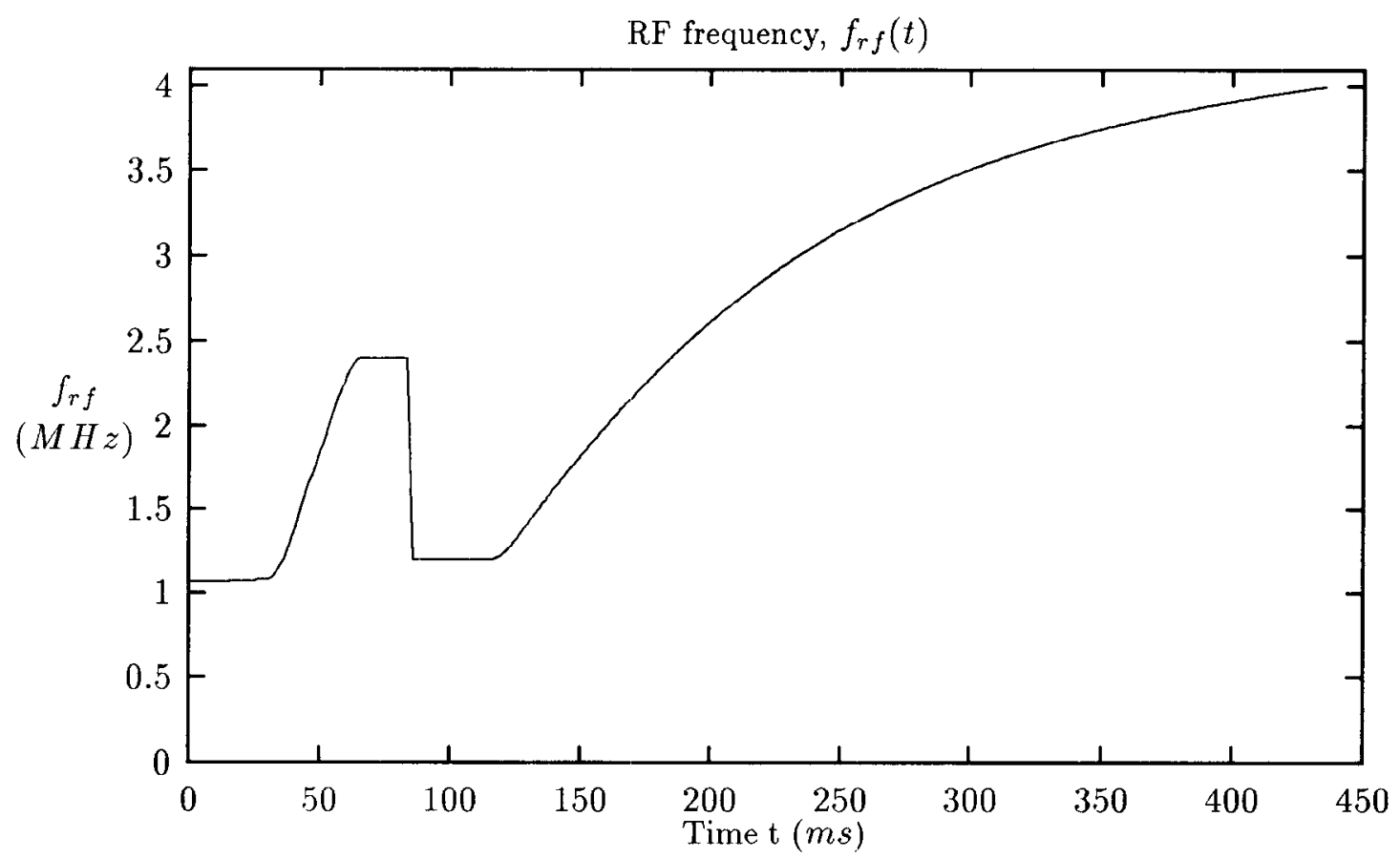

Figure 25: RF frequency vs. time. $S i^{+14}, h=6$.

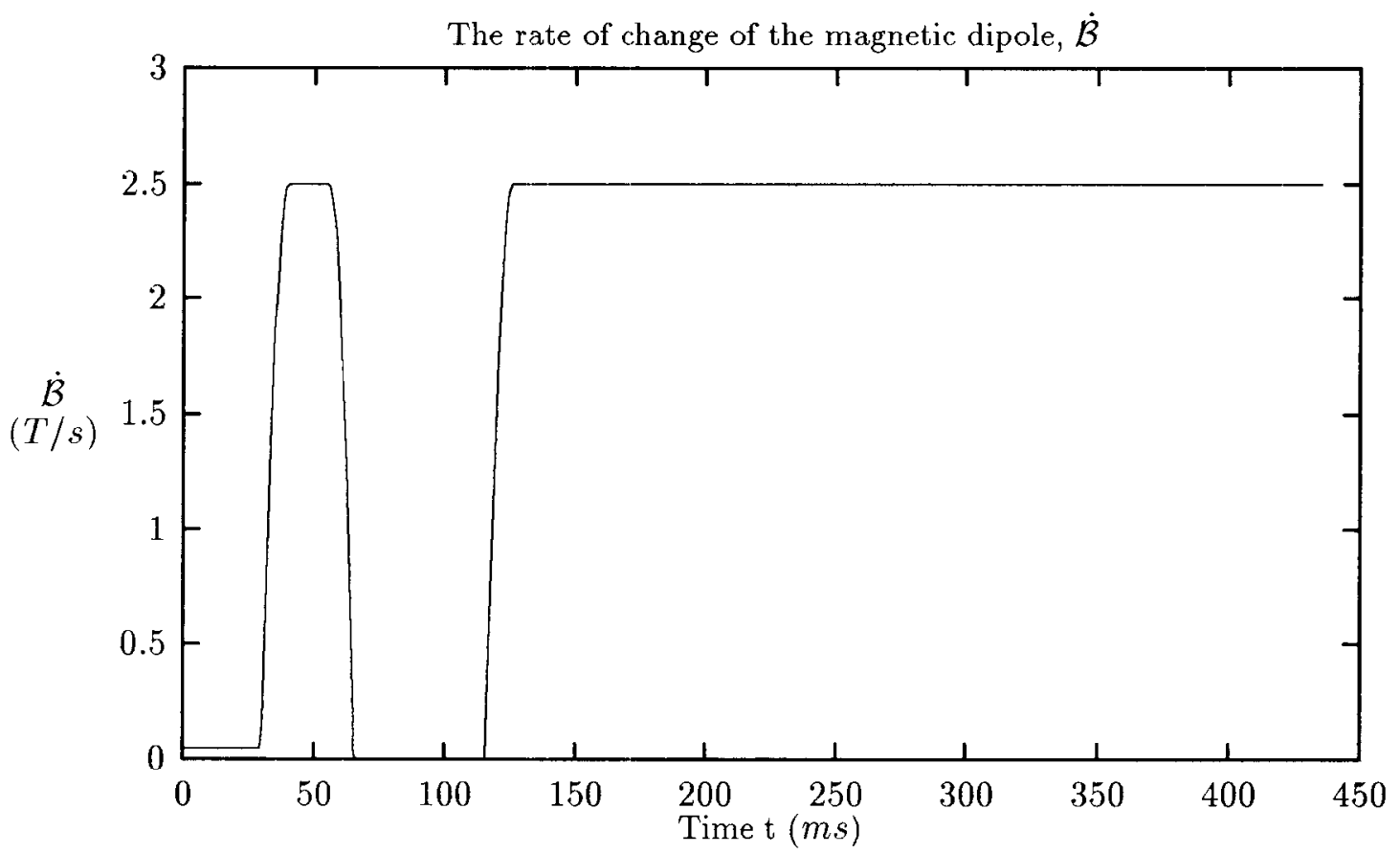

Figure 26: The rate of change of the magnetic dipole field vs. time. $S i^{+14}, h=6$. 


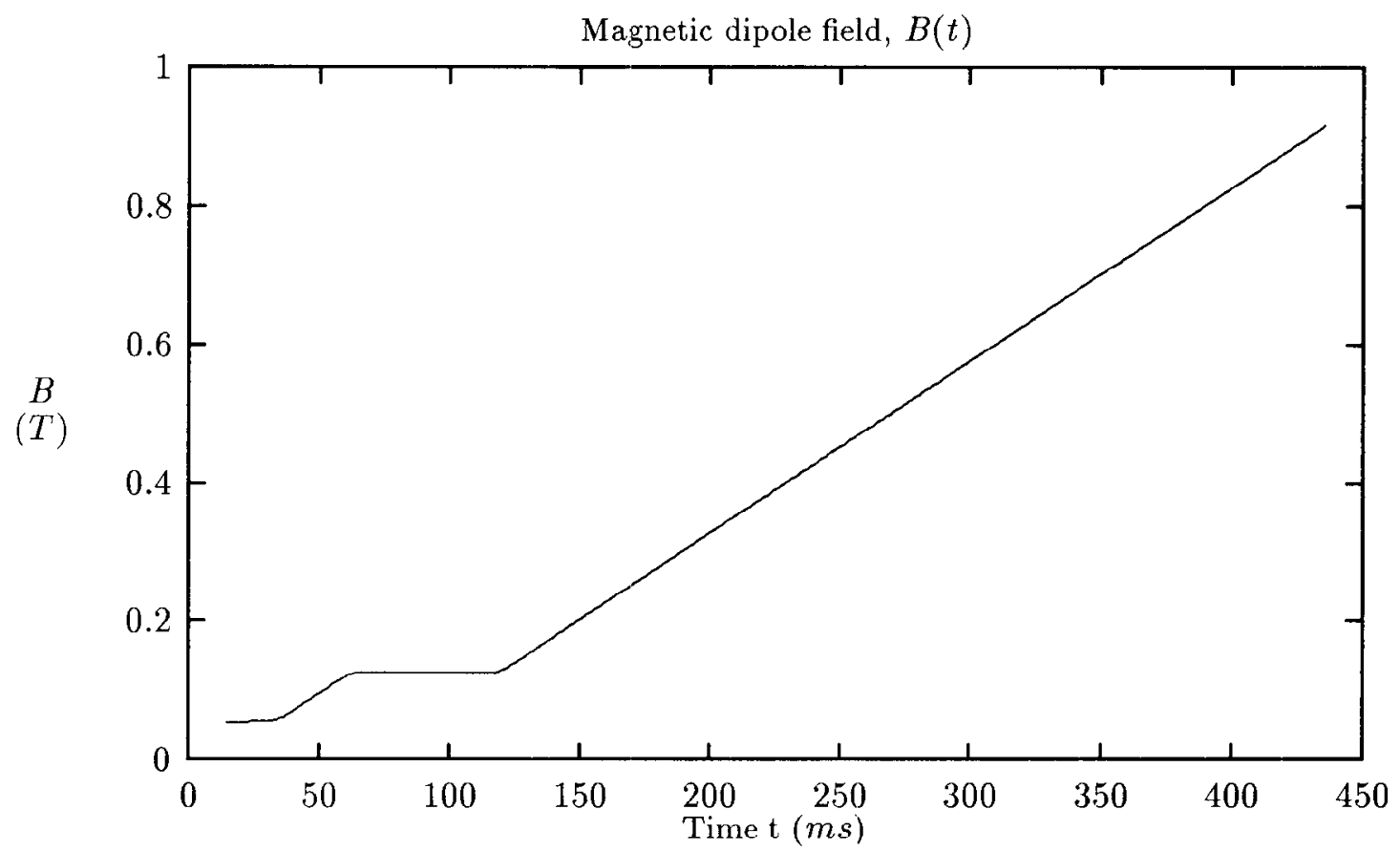

Figure 27: The magnetic dipole field vs. time. $S i^{+14}, h=6$.

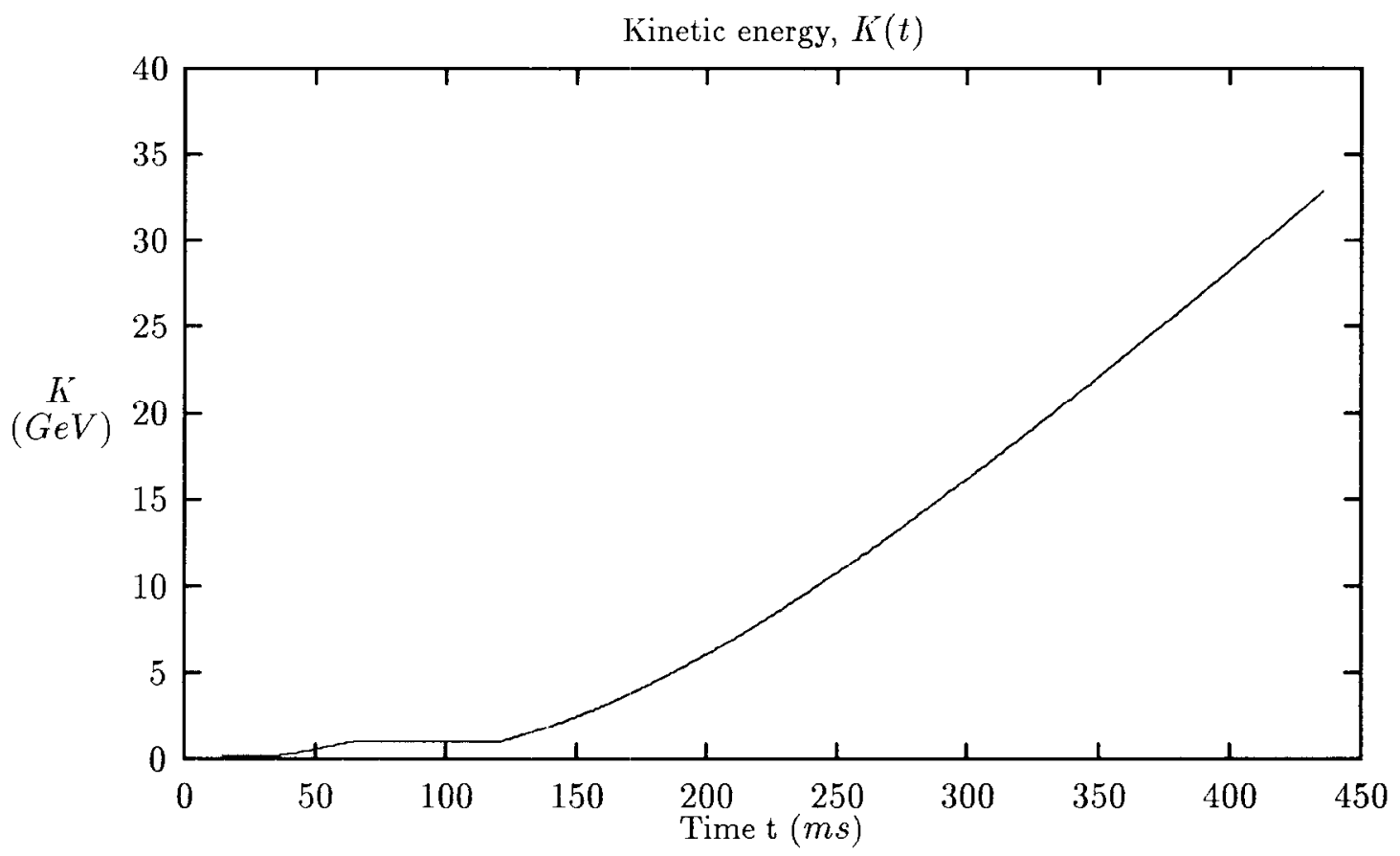

Figure 28: Kinetic energy vs. time. $S i^{+14}, h=6$. 


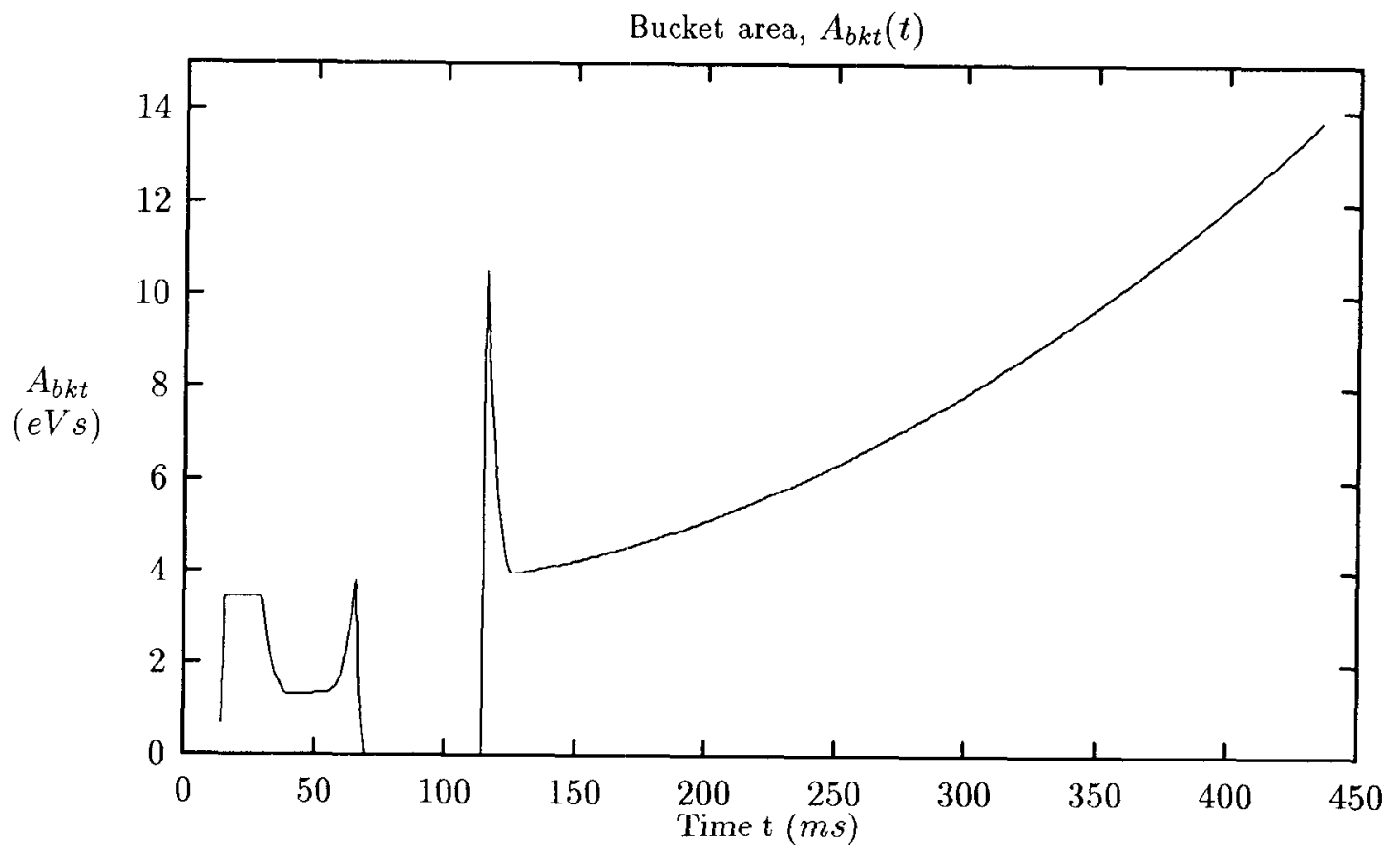

Figure 29: The bucket area vs. time. $S i^{+14}, h=6$.

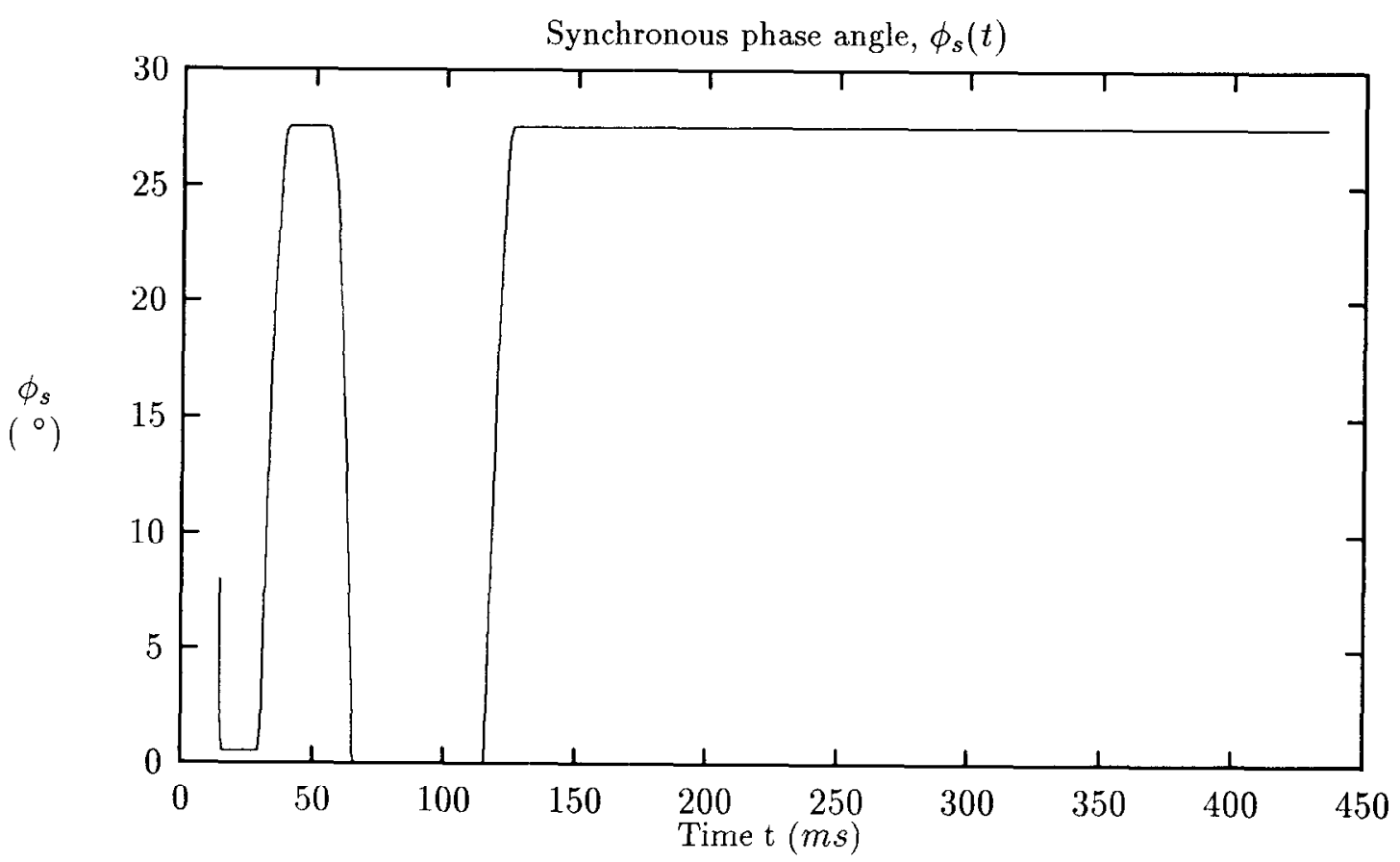

Figure 30: Synchronous phase angle vs. time. $S i^{+14}, h=6$. 


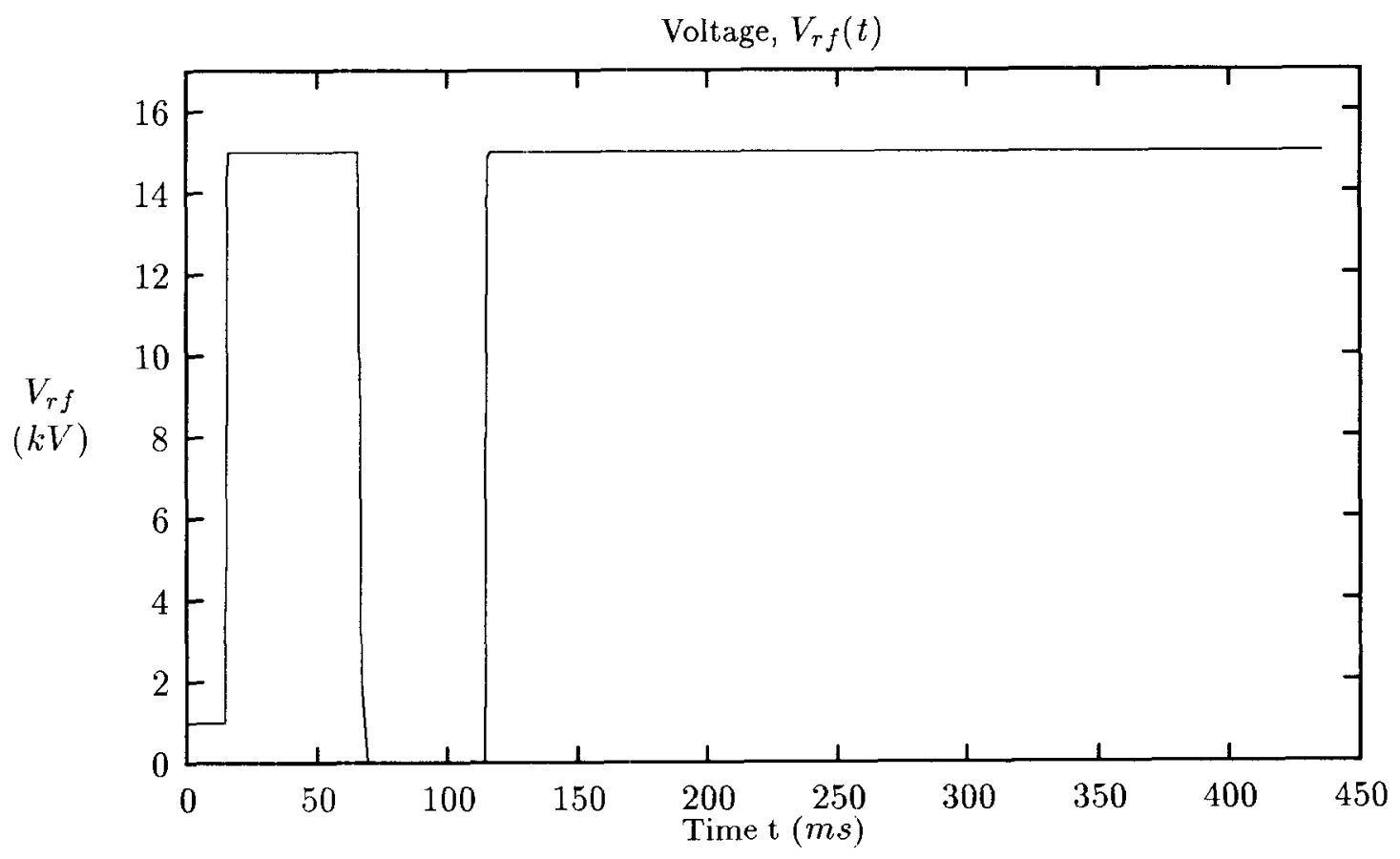

Figure 31: RF voltage vs. time. $S i^{+14}, h=6$.

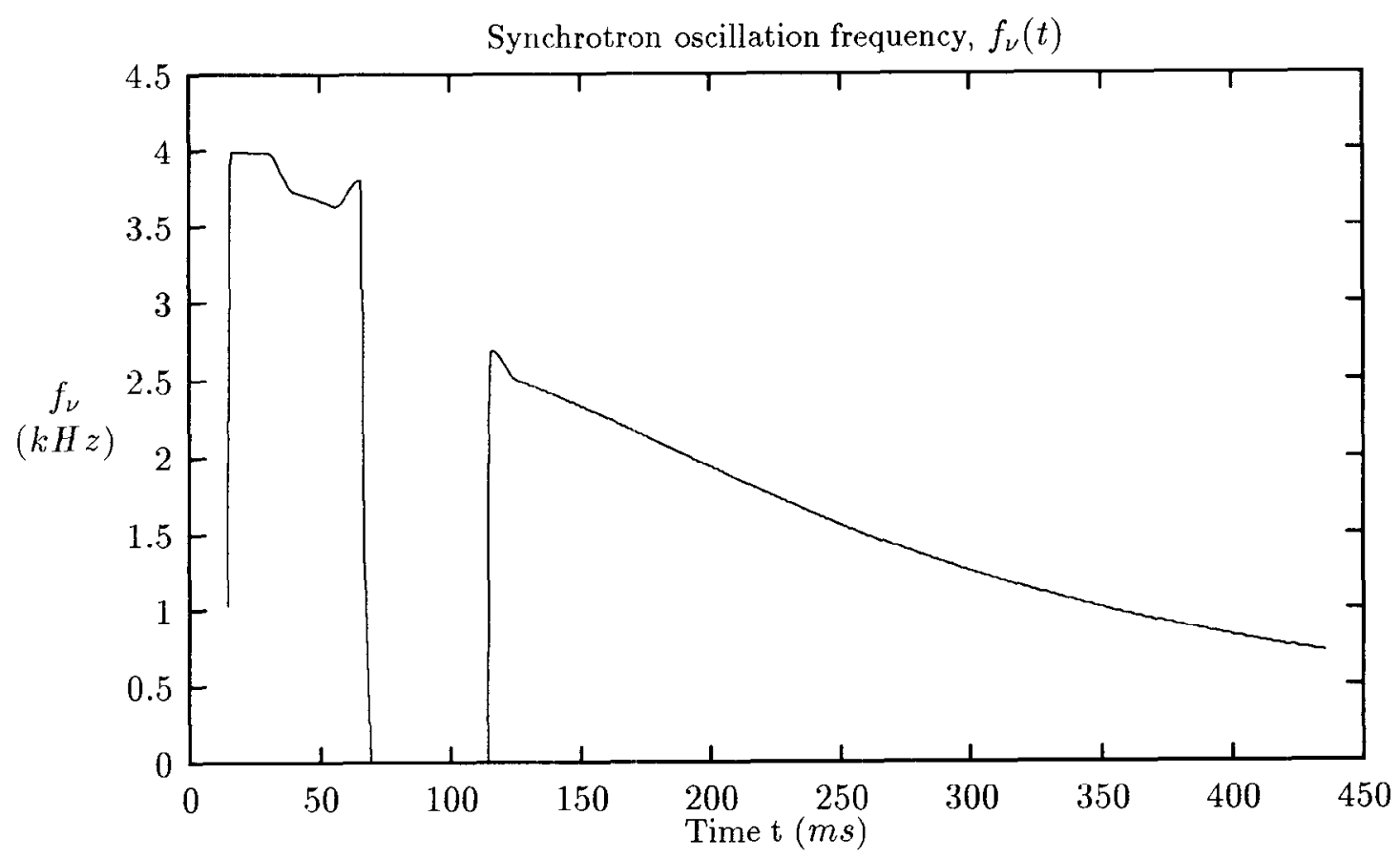

Figure 32: Synchrotron oscillation frequency vs. time. $S i^{+14}, h=6$. 


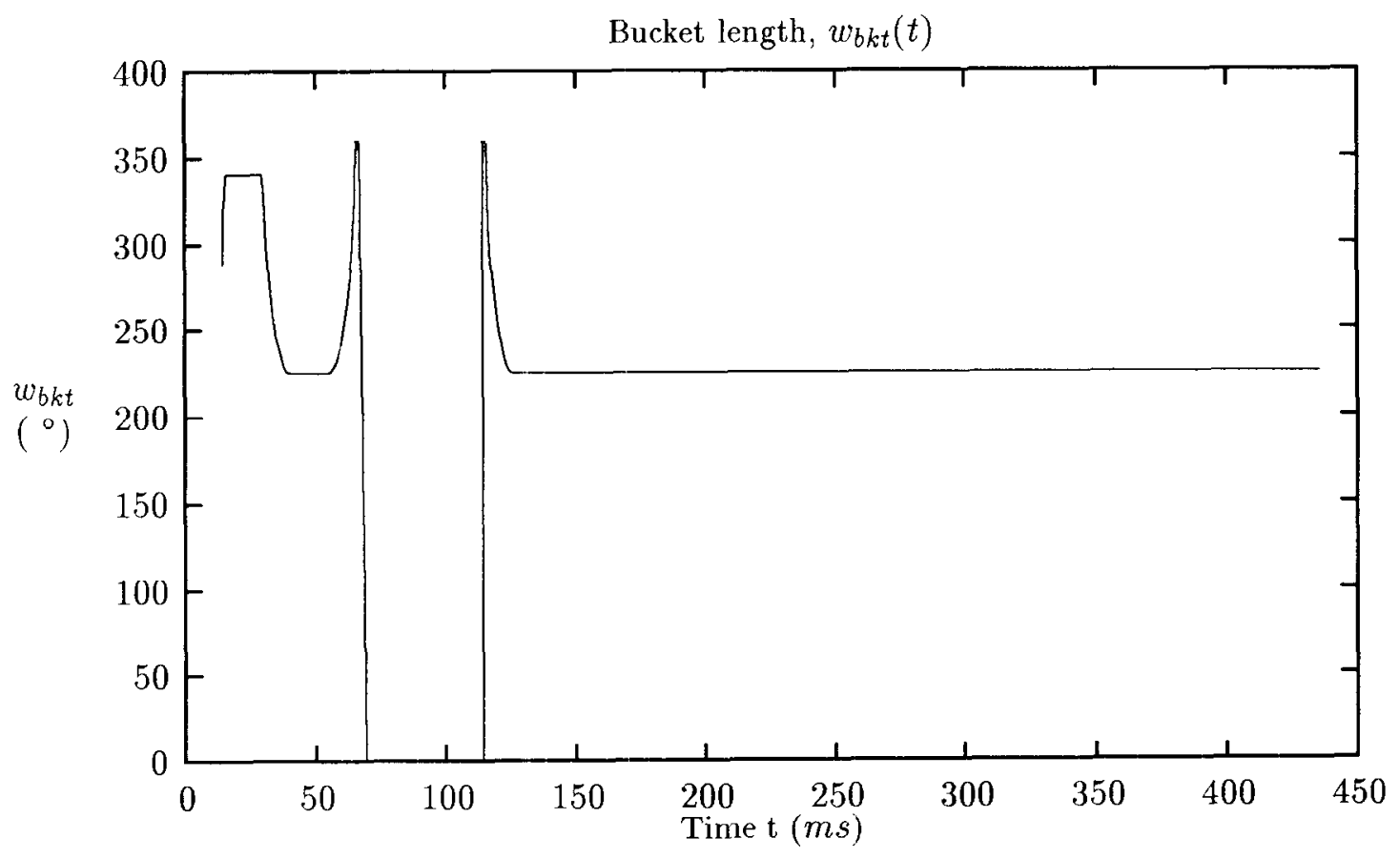

Figure 33: Bucket length (degree) vs. time. $S i^{+14}, h=6$.

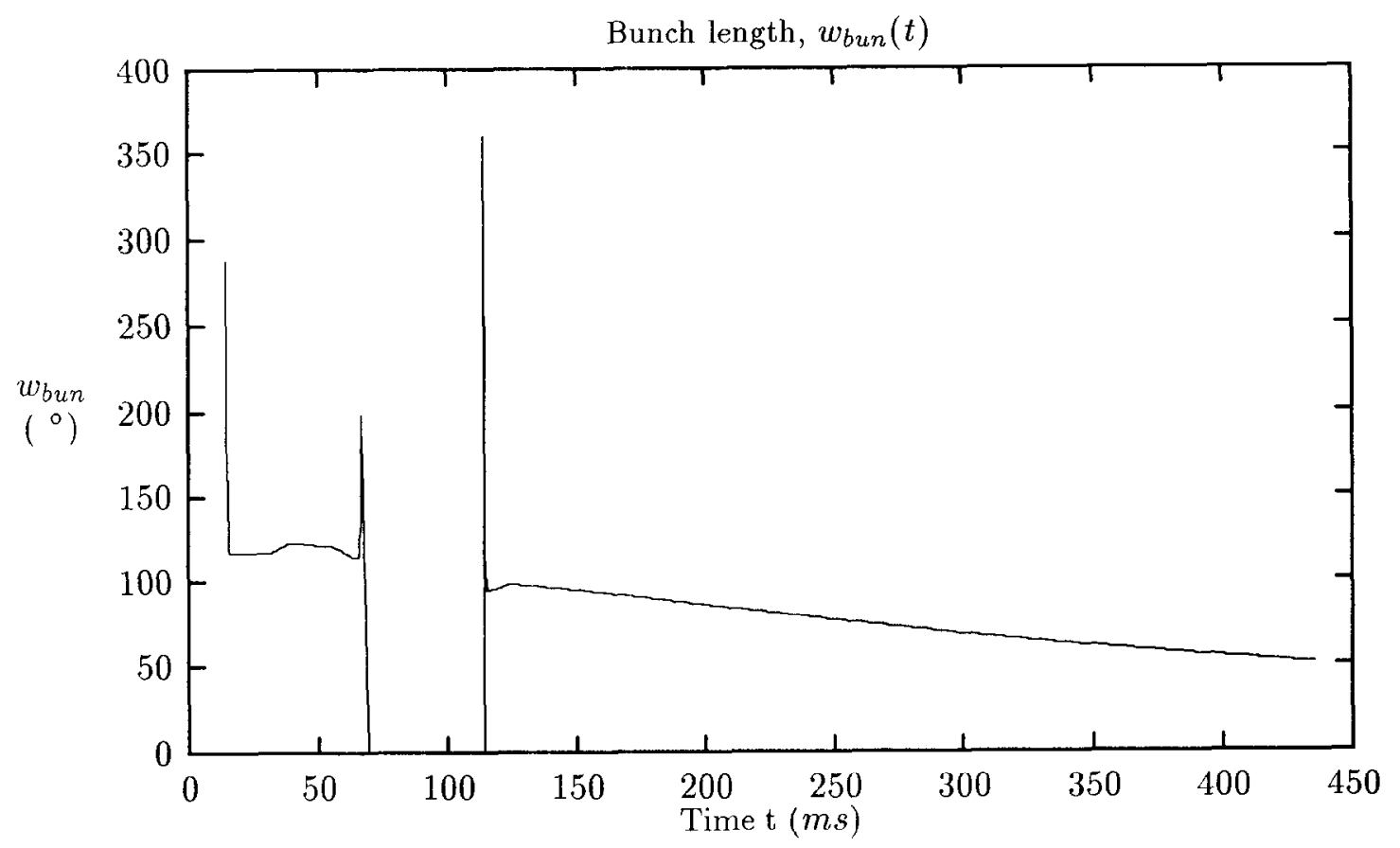

Figure 34: Bunch length (degree) vs. time. $S i^{+14}, h=6$. 


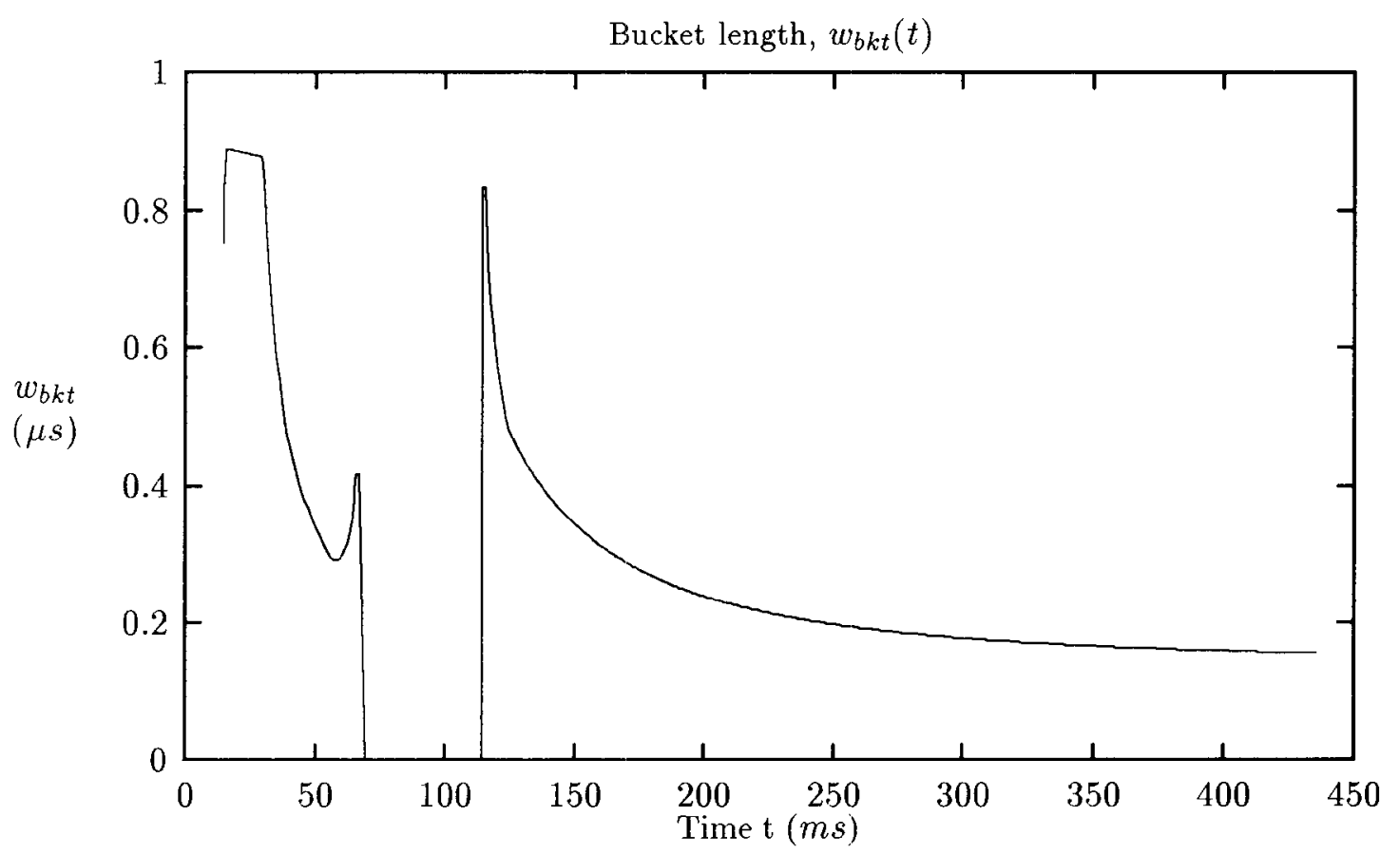

Figure 35: Bucket length $(m s)$ vs. time. $S i^{+14}, h=6$.

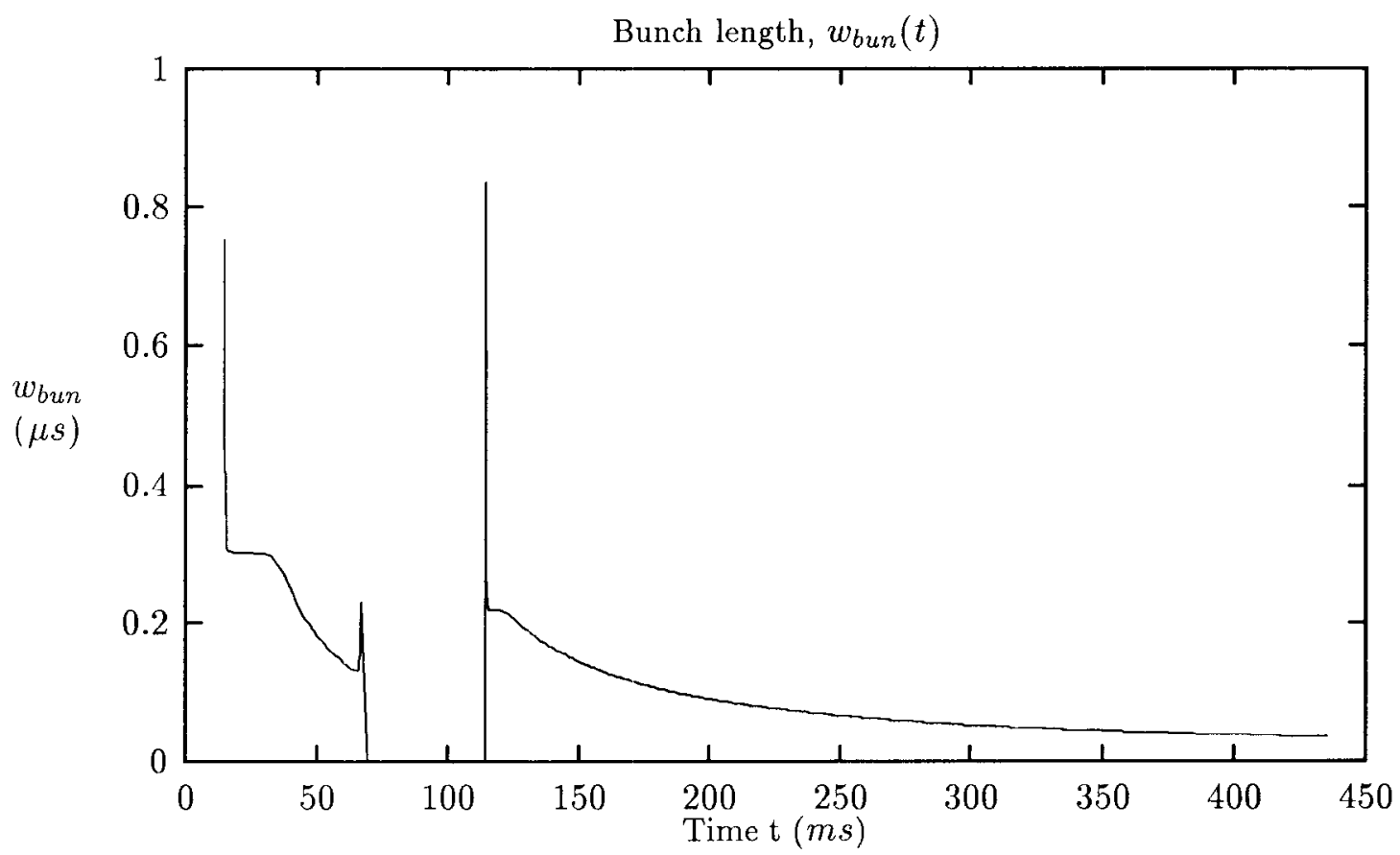

Figure 36: Bunch length $(m s)$ vs. time. $S i^{+14}, h=6$. 